\title{
¿Improvement of the Cloud Microphysics Scheme of the Mesoscale Model at the Japan Meteorological Agency Using Spaceborne Radar and Microwave Imager of the Global Precipitation Measurement as Reference
}

\author{
Yasutaka IKuta, ${ }^{\mathrm{a}}$ Masaki Satoh, ${ }^{\mathrm{b}}$ Masahiro Sawada, ${ }^{\mathrm{c}}$ Hiroshi Kusabiraki, ${ }^{\mathrm{c}}$ AND TaKuji Kubota ${ }^{\mathrm{d}}$ \\ ${ }^{\text {a }}$ Metrological Research Institute, Japan Meteorological Agency, Tsukuba, Japan \\ ${ }^{\mathrm{b}}$ Atmosphere and Ocean Research Institute, The University of Tokyo, Chiba, Japan \\ ${ }^{\mathrm{c}}$ Japan Meteorological Agency, Tsukuba, Japan \\ ${ }^{\mathrm{d}}$ Earth Observation Research Center, Japan Aerospace Exploration Agency, Tsukuba, Japan
}

(Manuscript received 20 March 2021, in final form 18 July 2021)

\begin{abstract}
In this study, the single-moment 6-class bulk cloud microphysics scheme used in the operational numerical weather prediction system at the Japan Meteorological Agency was improved using the observations of the Global Precipitation Measurement (GPM) core satellite as reference values. The original cloud microphysics scheme has the following biases: underestimation of cloud ice compared to the brightness temperature of the GPM Microwave Imager (GMI) and underestimation of the lower-troposphere rain compared to the reflectivity of GPM Dual-frequency Precipitation Radar (DPR). Furthermore, validation of the dual-frequency rate of reflectivity revealed that the dominant particles in the solid phase of simulation were graupel and deviated from DPR observation. The causes of these issues were investigated using a single-column kinematic model. The underestimation of cloud ice was caused by a high ice-tosnow conversion rate, and the underestimation of precipitation in the lower layers was caused by an excessive number of small-diameter rain particles. The parameterization of microphysics scheme is improved to eliminate the biases in the single-column model. In the forecast obtained using the improved scheme, the underestimation of cloud ice and rain is reduced. Consequently, the prediction errors of hydrometeors were reduced against the GPM satellite observations, and the atmospheric profiles and precipitation forecasts were improved.
\end{abstract}

KEYWORDS: Cloud microphysics; Microwave observations; Radars/Radar observations; Satellite observations; Model evaluation/performance; Numerical weather prediction/forecasting

\section{Introduction}

Design and details of cloud microphysics schemes in a numerical weather prediction (NWP) model significantly affect the prediction accuracy of mesoscale systems, particularly the prediction of precipitation and hydrometeors. With the progress of global Earth observation satellite missions, satellite observations can now be used to verify simulated hydrometeors in numerical models (Masunaga et al. 2008; Eito and Aonashi 2009; Matsui et al. 2009; Hashino et al. 2013; Kotsuki et al. 2014; Swales et al. 2018). Based on a comparison of the cloud and precipitation properties between satellite observations and model results, studies are being conducted to improve the cloud microphysics scheme in numerical models (Li et al. 2010; Roh and Satoh 2014; Roh et al. 2017, 2020; Kuba et al. 2020).

Spaceborne precipitation radars that can observe threedimensional (3D) reflectivity data using the Tropical Rainfall Measuring Mission/Precipitation Radar (TRMM/PR; Kummerow et al. 1998; Kozu et al. 2001) and Global Precipitation Measurement/Dual-frequency Precipitation Radar (GPM/DPR; Kojima et al. 2012; Hou et al. 2014; Skofronick-Jackson et al. 2017;

\footnotetext{
๑ Denotes content that is immediately available upon publication as open access.
}

Corresponding author: Yasutaka Ikuta, yasutaka.ikuta@mrijma.go.jp
Iguchi 2020) depict the 3D structure of precipitation systems. The TRMM/PR is a Ku-band precipitation radar, and the GPM/DPR consists of a Ku-band precipitation radar (KuPR) and a Ka-band precipitation radar (KaPR). The 3D reflectivity data are useful for comparing satellite observations with predicted hydrometeors. TRMM Microwave Imager (TMI) and GPM Microwave Imager (GMI), which are loaded on the same platform as the spaceborne precipitation radar, provide horizontal distribution of the precipitation information, which can be used for model validation. These microwave imagers can detect microwave signals that are scattered by cloud ice at a high-frequency band over $89 \mathrm{GHzV}$ (where $\mathrm{V}$ is a vertically polarized wave element) and can be used for cloud ice validation. Simultaneous observations using radar and microwaves from space are beneficial in evaluating the 3D structure of precipitation systems in numerical models (Matsui et al. 2009, 2016; Chern et al. 2020).

Eito and Aonashi (2009) validated the NWP model using TRMM/PR, TMI, and ground radar and quantified the errors in the cloud microphysics scheme. Matsui et al. (2009) proposed a validation method for a cloud-resolving model (CRM) using the multiple sensors of TRMM/PR and TMI, called TRMM TripleSensor Three-Step Evaluation Framework (T3EF). Hashino et al. (2013, 2016) compared CloudSat, CALIPSO, and Clouds and the Earth's Radiant Energy System Aqua with models using the Joint Simulator for Satellite Sensors, which is a package of highly accurate satellite simulators developed for the EarthCARE satellite mission (Illingworth et al. 2015). 
Duruisseau et al. (2018) validated the model by simulating GPM/DPR and CloudSat/CPR using the enhanced rapid radiative transfer for TOVS for scattering (RTTOV-SCATT; Bauer et al. 2006; Saunders et al. 2018) developed by EUMETSAT. Roh and Satoh (2014) and Roh et al. (2017) improved the cloud microphysics scheme of a CRM based on T3EF. Roh et al. (2017) extended a multisensor satellite radiance-based evaluation for CRMs. Roh et al. (2020) proposed a model validation method of thermodynamics of hydrometeors using the depolarization ratio and total attenuated backscatters of CALIPSO.

In the field of operational data assimilation, the bias between observations and simulations is a critical factor affecting the analysis accuracy. Okamoto et al. (2016) showed the existence of model bias by comparing GPM/DPR and models, and Ikuta et al. (2021) corrected the bias using GPM/DPR in assimilation. Fielding and Janisková (2020) highlighted the necessity to correct the bias in CloudSat direct assimilation. To assimilate microwaves, such as GPM/GMI, it is assumed that a systematic bias exists over cloud regions between models and observations; these biases must be carefully corrected before assimilation (Geer and Bauer 2011). Results of previous studies indicate that the prediction accuracy of models and analysis accuracy of spaceborne radar and microwave assimilation depend on the predicted hydrometeors in the models (Chambon et al. 2014; Geer et al. 2018).

NWP models of the Japan Meteorological Agency (JMA) have been improved by focusing on the forecast accuracy of precipitation, atmospheric temperature, and water vapor (Japan Meteorological Agency 2020). However, relatively less attention has been devoted to the improvement of the prediction accuracy of hydrometeors in the atmosphere. In this study, we use GPM/DPR and GMI to evaluate hydrometeors of the NWP model of JMA and improve the cloud microphysics scheme implemented in the NWP model.

Furthermore, to save computational resources, cloud microphysics schemes in NWP models must not be complex; thus, it is difficult to implement multimoment schemes or spectral bin schemes for NWP models. The JMA's operational mesoscale model adapts a single-moment bulk microphysics scheme; a new scheme within the same framework is proposed herein. An elaborated scheme that captures realistic cloud physics in a specific case does not necessarily reproduce better hydrometeor fields. Rather, forecasting ability eventually depends on the total balance of the details of NWP models.

In this study, the biases of hydrometeors of the original cloud microphysics scheme in the operational mesoscale model are identified using GPM observations and a new cloud microphysics scheme that reduces these biases is constructed. The structure of this paper is as follows. Section 2 provides an overview of the I-simulator and cloud microphysics scheme in the mesoscale model (MSM) of JMA. Section 3 introduces a new scheme and shows the impacts of the new scheme by comparing it with the original scheme using the GPM/DPR and GMI observation via a case study. In section 4, the modification effects of the cloud microphysics scheme are clarified using a single-column kinematic mode. In section 5, we statistically verify the prediction accuracy of MSM by comparing the original and new cloud microphysics schemes. Section 6 concludes and discusses an approach for improving cloud microphysics schemes in NWP models.

\section{Methods}

\section{a. JMA mesoscale model}

The JMA operates the MSM to provide disaster prevention information. The MSM is a nonhydrostatic model. The horizontal grid spacing is $5 \mathrm{~km}$, with $817 \times 661$ grid points; the model height is approximately $21.8 \mathrm{~km}$, with 76 vertical layers. The forecast area covers all of Japan and its surrounding areas. The Global Spectral Model at JMA provides the boundary condition. The MSM runs eight times a day, every $3 \mathrm{~h}$. The integration time of the forecast is $39 \mathrm{~h}$, with a time step of $100 / 3 \mathrm{~s}$, but the integration time of the forecast from the initial condition at 0000 and 1200 UTC is $51 \mathrm{~h}$. In the operational MSM, the cloud microphysics scheme called MP1702 was used before this study. Details about the MSM and MP1702 can be found in the JMA's NWP outline (Japan Meteorological Agency 2019).

We describe the parts of the cloud microphysics scheme relevant to this study. MP1702 is a 6-class 3-ice bulk cloud microphysics scheme (Japan Meteorological Agency 2019). The mixing ratios of water vapor $\left(q_{v}\right)$, cloud water $\left(q_{c}\right)$, rain $\left(q_{r}\right)$, cloud ice $\left(q_{i}\right)$, snow $\left(q_{s}\right)$, and graupel $\left(q_{g}\right)$ constitute prognostic variables. In the MP1702 scheme, a cloud distribution in the model's grid box is provided a cloud fraction of ice $\left(C_{i}\right)$ and a cloud fraction of liquid $\left(C_{l}\right)$. The total cloud fraction in the grid box $(C)$ is given as

$$
C=C_{i}+C_{l}-\min \left(C_{i}, C_{l}\right),
$$

where the third term of the right hand side of Eq. (1) means a cloud fraction of mixed phase. The cloud fraction of liquid is provided by the method of Smith (1990). The shape of PDF for the cloud fraction is triagonal, which is the same as in Smith (1990). The critical relative humidity for the commencement of cloud formation is set at $95 \%$. The cloud fraction of ice cloud is provided by the method of Wilson and Ballard (1999).

The particle size distribution (PSD) of cloud water is monodispersive. The concentration of cloud water is fixed at $1.0 \times$ $10^{8} \mathrm{~m}^{-3}$. The PSD of rain is provided by Abel and Boutle (2012) (hereafter referred to AB). The concentration of rain as a function of diameter $D(\mathrm{~m})$ is given as

$$
n_{r}(D)=x_{1} \lambda_{r}^{x_{2}} \exp \left(-\lambda_{r} D\right)
$$

where $\lambda_{r}\left(\mathrm{~m}^{-1}\right)$ is a slope parameter, $x_{1}=26.2 \mathrm{~m}^{x_{2}-4}$, and $x_{2}=$ 1.57. The PSD of snow is provided by Field et al. (2007). The PSD of cloud ice and graupel is a negative exponential distribution, but the intercept parameter for cloud ice depends on temperature. The mass of ice and snow is defined by Brown and Francis (1995). The terminal velocity of hydrometeor particles is given as

$$
V_{T_{x}}=\left(\frac{\rho_{0}}{\rho_{\mathrm{a}}}\right)^{0.5} \sum_{k=1}^{2} c_{k x} D_{x}^{d_{k x}} e^{-f_{k x} D_{x}},
$$


TABLE 1. Parameters of terminal velocity in MP1702 and MP2003. Units for $c_{k x}$ and $f_{k x}$ are $\mathrm{m}^{1-d_{k x}} \mathrm{~s}^{-1}$ and $\mathrm{m}^{-1}$, and $d_{k x}$ is dimensionless; $x \in(r, i, s, g) ; k=1,2$. We ignore $c_{2 x}, d_{2 x}$, and $f_{2 x}$, except for the rain particle of MP1702.

\begin{tabular}{ccccc}
\hline \hline & Rain & Cloud ice & Snow & Graupel \\
\hline MP1702 & $c_{1 r}=4854.1, c_{2 r}=-446.009$ & $c_{1 i}=124.0$ & $c_{1 s}=17.0$ & $c_{1 g}=124.0$ \\
& $d_{1 r}=1.0, d_{2 r}=0.782127$ & $d_{1 i}=0.67862$ & $d_{1 s}=0.5$ & $d_{1 g}=0.64$ \\
& $f_{1 r}=195.0, f_{2 r}=4085.35$ & $f_{1 i}=0.0$ & $f_{1 s}=0.0$ & $f_{1 g}=0.0$ \\
(Abel and Shipway 2007) & (Japan Meteorological Agency 2019) & (Murakami 1990) & (Murakami 1990) \\
MP2003 & $c_{1 r}=842.0$ & $c_{1 i}=71.34$ & As in MP1702 & As in MP1702 \\
& $d_{1 r}=0.8$ & $d_{1 i}=0.6635$ & & \\
& $f_{1 r}=0.0$ & $f_{1 i}=0.0$ & & \\
& (Lin et al. 1983) & (Ferrier et al. 1995) & & \\
\hline
\end{tabular}

where $D_{x}$ is the diameter of category $x, \rho_{a}$ is the density of air, and $\rho_{0}$ is the density of the reference air. The parameters $c_{k x}, d_{k x}$ and $f_{k x}$ are described in the MP1702 rows of Table 1. Note that particles of cloud water do not fall. The autoconversion scheme from cloud to rain is provided by the Kessler-type as

$$
\mathrm{QCN}_{c r}=K_{1} \max \left(q_{c}-q_{c 0}, 0\right)
$$

where $K_{1}=0.001 \mathrm{~s}^{-1}$ and $q_{c 0}=1.0 \times 10^{-5} \mathrm{~kg} \mathrm{~kg}^{-1}$. The autoconversion scheme from cloud ice to snow is given as

$$
\mathrm{QCN}_{i s}=\max \left[K_{2} \max \left(q_{i}-q_{i 0}, 0\right), f_{\mathrm{AGG}} \frac{q_{i}}{\Delta t}\right],
$$

where $\Delta t$ is the time step, $K_{2}=0.001 e^{0.025(T-273.15)} \mathrm{s}^{-1}$ and $q_{i 0}=1.0 \times 10^{-4} \mathrm{~kg} \mathrm{~kg}^{-1}$. The fraction $f_{\mathrm{AGG}}$ to split between ice and aggregates is given as

$$
f_{\mathrm{AGG}}=1-\exp \left(-T_{0} \Delta T \frac{q_{i}}{q_{i 0}}\right),
$$

where $T_{0}=0.0384 \mathrm{~K}^{-1}$ and $\Delta T$ is the temperature increase from the cloud top (Cotton et al. 2013). The collection rate when category $x$ collects category $y$ is calculated by

$$
\begin{aligned}
\mathrm{QCL}_{y x}= & \frac{1}{\rho_{\mathrm{a}}} \frac{\pi}{4} \iint E_{x y}\left|V_{T_{x}}\left(D_{x}\right)-V_{T_{y}}\left(D_{y}\right)\right|\left(D_{x}\right. \\
& \left.+D_{y}\right)^{2} m_{y}\left(D_{y}\right) n_{x}\left(D_{x}\right) n_{y}\left(D_{y}\right) d D_{x} d D_{y},
\end{aligned}
$$

where $x$ and $y$ are the category of hydrometeors, $m_{y}$ is the mass of category $y$, and $E_{x y}$ is the collection efficiencies. We set $E_{x y}=1$, except for $E_{s i}=0.02 \exp \left(0.08 T_{c}\right)$ and $E_{g i}=$ $0.01 \exp \left(T_{c}\right)$, where $T_{c}$ is the air temperature of air in degrees Celsius. In the case of collecting cloud water and cloud ice, $V_{T_{y}}$ is ignored for simplification.

In this study, we propose a new scheme, MP2003, which is a revised version of MP1702 and is obtained using the verification results described in sections $3-5$. In the proposed scheme, we introduce the following changes. First, the PSD of rain is replaced by the Marshal-Palmer (MP) distribution (instead of the $\mathrm{AB}$ scheme). The PSD of rain is defined as a negative exponential form of MP, provided by Eq. (2) with $x_{1}=8 \times 10^{6} \mathrm{~m}^{-4}$ and $x_{2}=0$. Figure 1 shows the PSD of MP and AB. The concentration of $\mathrm{AB}$ is more than that of $\mathrm{MP}$ in the small-diameter regions. Figure 2 shows the terminal velocities of hydrometeor. The terminal velocity of rain and cloud ice is redefined as in the MP2003 rows of Table 1. The second change in MP2003 is in the autoconversion of cloud water to rain, where the threshold $q_{c 0}$ is changed to $1.0 \times 10^{-3} \mathrm{~kg} \mathrm{~kg}^{-1}$ shown in Fig. 3. Third, the fraction $f_{\mathrm{AGG}}$ is disabled to work in $\mathrm{QCN}_{i s}$ (see Fig. 4). In the collection equation, the terminal velocity of cloud ice is not ignored and the collection efficiencies of snow and cloud ice are given as $E_{s i}=0.05 \exp \left(0.1 T_{c}\right)$, following Ferrier et al. (1995). In section 3, we describe via a case study how these changes improve the biases, and in section 4, we show the impacts of each change separately using a single-column kinematic model.

\section{b. Integrated satellite simulators}

From the output data of the MSM simulation, the sensor signals of GPM (DPR, GMI) are simulated using satellite simulators for each sensor. The package of the satellite simulators used at JMA is referred to as the I-simulator, which is described here.

For GMI, we use RTTOV-SCATT. The coefficient files used for radiation transfer calculations were recreated based on the cloud microphysics scheme in the MSM configurations. Cloud water, rain, cloud ice, snow, and graupel are effective hydrometeors. Particles of cloud water, rain, and graupel are spherical

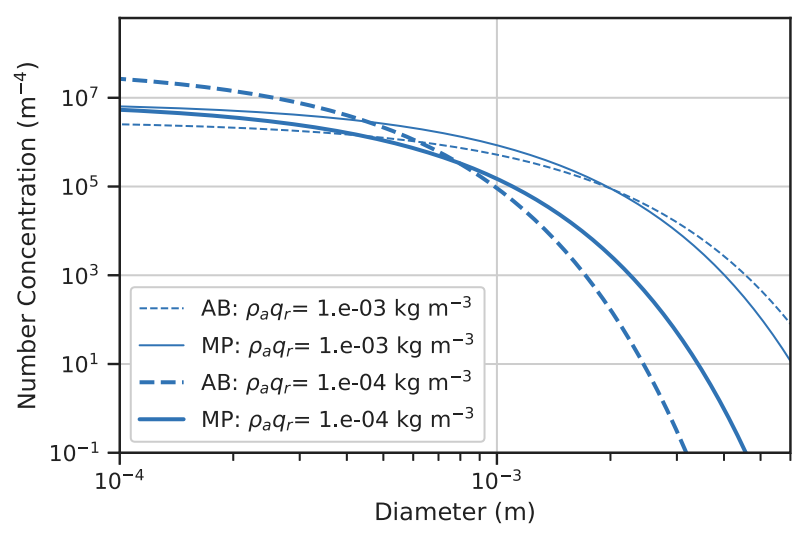

FIG. 1. Particle size distribution (PSD) as a function of diameter. The thin lines show the concentration at $\rho_{a} q_{r}=1.0 \times 10^{-3} \mathrm{~kg} \mathrm{~m}^{-3}$; the thick lines show the concentration at $\rho_{a} q_{r}=1.0 \times 10^{-4} \mathrm{~kg} \mathrm{~m}^{-3}$. The solid (dashed) lines show the PSD of AB (MP). 


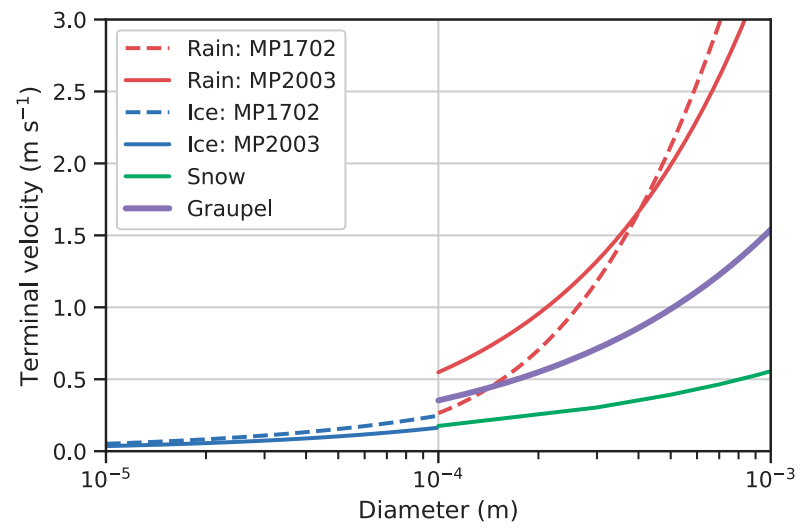

FIG. 2. Terminal velocities of rain, ice, snow, and graupel as a function of diameter. The solid (dashed) lines show the terminal velocities in MP2003 (MP1702) simulation.

whereas that of cloud ice and snow are in the shape of thick hex plates and Liu's type-A snowflake (Liu 2008), respectively. The cloud fraction in the cloud microphysics scheme (see section $2 \mathrm{a}$ ) determines the cloud cover in the grid. The definitions of particle mass and size distribution are the same as those of MSM.

For DPR simulations, we developed a DPR simulator. The DPR simulator is an extended version of the radar simulator developed as an observation operator in DPR assimilation (Ikuta et al. 2021). The observation operator for the assimilation is a very simplified simulator that ignore cloud particle and uses only Mie scattering. On the other hand, this study mainly enhances the scattering calculation process in the I-simulator. The DPR simulator should verify the microphysics of clouds in NWP model so that it can perform more advanced simulations than those used in data assimilation. An overview is given here. The particles used in the DPR simulations are cloud water, rain, cloud ice, snow, and graupel. Particles of cloud water, rain, and graupel particles are assumed to be spherical. Particles of cloud ice and snow

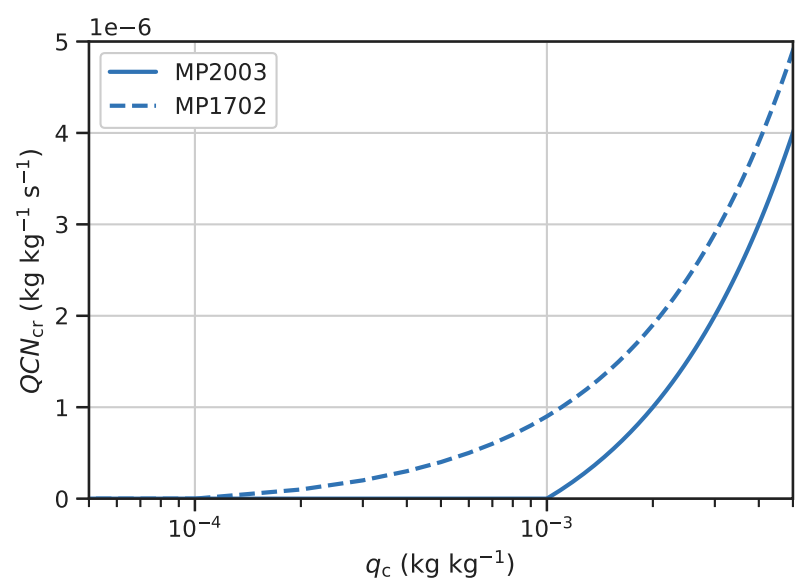

FIG. 3. Autoconversion tendencies from cloud water to rain in MP1702 (dashed line) and MP2003 (solid line) simulation as given by Eq. (4).

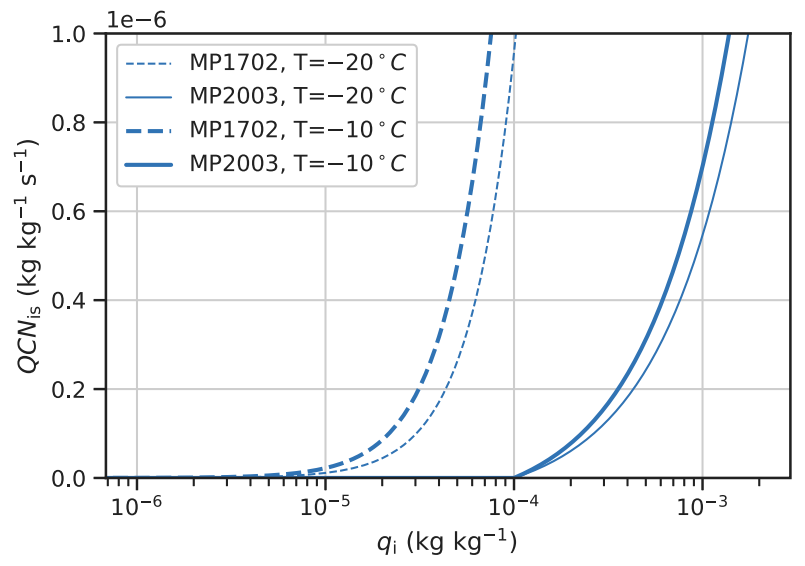

FIG. 4. Autoconversion tendencies from cloud ice to snow in MP1702 (dashed line) and MP2003 (solid line) simulation according to Eq. (5), and correspond to the temperature at cloud top is $-30^{\circ} \mathrm{C}$ and $\Delta t=100 / 3 \mathrm{~s}$. The thin and thick lines show the tendencies in $T=-20^{\circ} \mathrm{C}$ and $T=-10^{\circ} \mathrm{C}$, respectively.

are in the shape of hex plate and sector-like defined by Liu's sector snowflakes (Liu 2008). Scattering coefficients are derived from the scattering database (http://cirrus.met.fsu.edu/ research/scatdb.html; Liu 2008).

The DPR simulation is given by the following procedure regarding the GPM/DPR Level-2 algorithm (Iguchi et al. 2018; Seto et al. 2021). The effective radar reflectivity factor is given as

$$
Z_{e}=\frac{\lambda^{4}}{\pi^{4}|K|^{2}} \int \sigma_{b} n(D) d D,
$$

where $\lambda(\mathrm{m})$ is the wavelength of the radar, $K=\left(m^{2}-1\right) /\left(m^{2}+\right.$ $2), m$ is the complex refractive index, $\sigma_{b}\left(\mathrm{~m}^{2}\right)$ is a backscattering cross section of hydrometeor particles, $n(\cdot)\left(\mathrm{m}^{-4}\right)$ is a PSD function, and $D(\mathrm{~m})$ is diameter. The precipitationspecific attenuation $k\left(\mathrm{~dB} \mathrm{~km}^{-1}\right)$ is given as

$$
k=c_{k} \int \sigma_{e} n(D) d D,
$$

where $c_{k}=0.01 \ln (10)$ and $\sigma_{e}\left(\mathrm{~m}^{2}\right)$ is the total extinction cross section. The attenuation is integrated from space to the target altitude. The measured reflectivity factor $Z_{m}$ is given as

$$
10 \log _{10} Z_{m}=10 \log _{10} Z_{\mathrm{e}}-2 \int_{0}^{r} k(s) d s
$$

where $r$ is the length of the integrated path from the satellite to the target altitude. The measured dual-frequency rate $\left(\mathrm{DFR}_{m}\right.$; Le and Chandrasekar 2013) is defined as

$$
\mathrm{DFR}_{m}=Z_{m}(\mathrm{Ku})-Z_{m}(\mathrm{Ka}),
$$

where $Z_{m}(\mathrm{Ku})$ is the reflectivity of $\mathrm{KuPR}$ and $Z_{m}(\mathrm{Ka})$ is the reflectivity of $\mathrm{KaPR}$. $\mathrm{DFR}_{m}$ is calculated only at the point where both $Z_{m}(\mathrm{Ku})$ and $Z_{m}(\mathrm{Ka})$ exist. The $\sigma_{b}$ and $\sigma_{e}$ are stored in advance in a database for each particle type. 

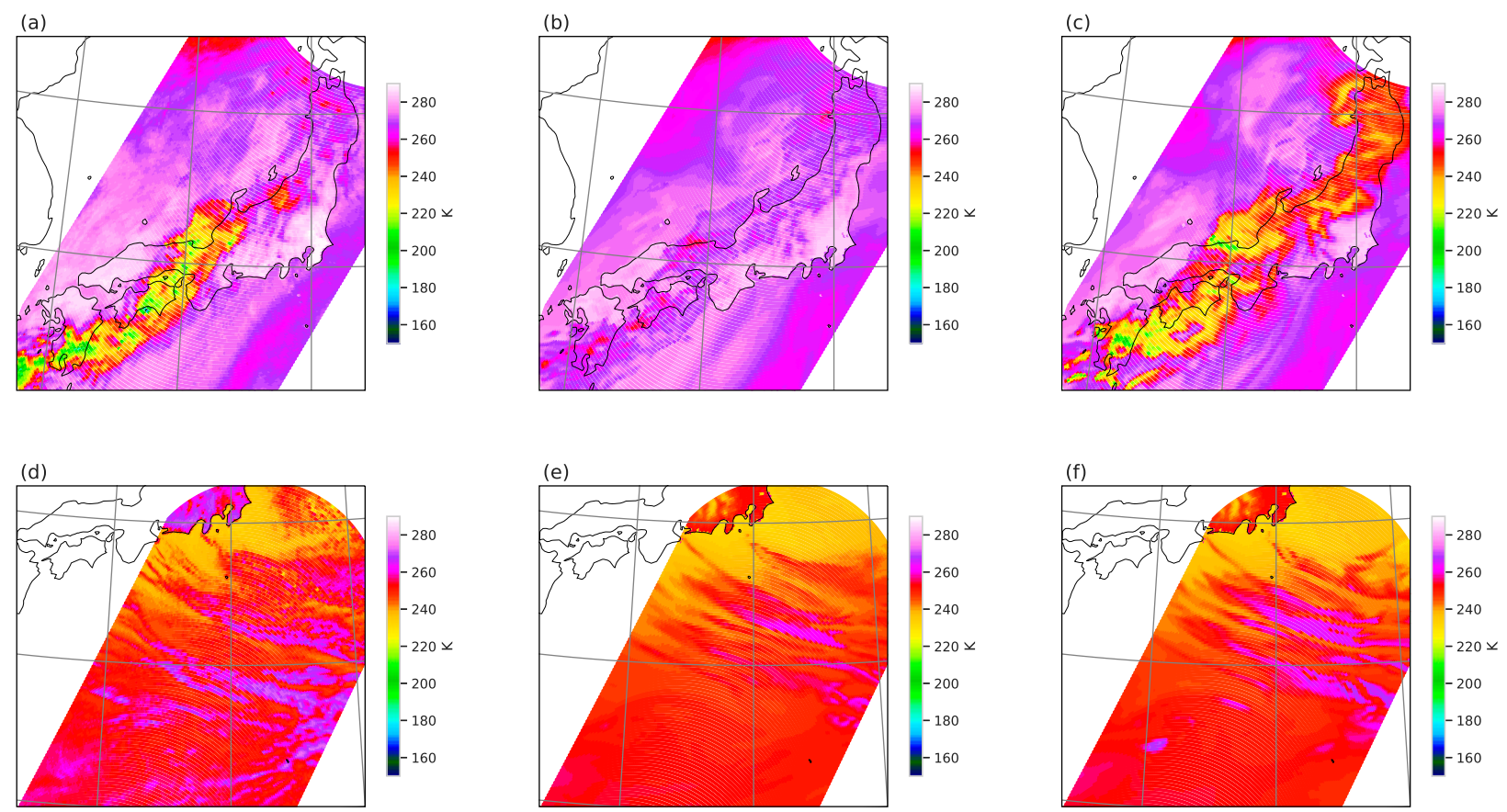

FIG. 5. $T_{B}$ at $89 \mathrm{GHzV}$ of (a),(d) GMI observation; (b),(e) MP1702 simulation; and (c),(f) MP2003 simulation. (top) $T_{B}$ at $0000 \mathrm{UTC} 7 \mathrm{Jul}$ and (bottom) $T_{B}$ at 0600 UTC 3 Jan 2018.

For the actual calculation, the scattering coefficients for each particle are obtained using the LUT method using the database, integrated by the particle size, and then summed for all the particles. The simulated $\mathrm{DFR}_{m}$ is a signal that cancels out almost of the bias caused by the error in the assumption of simulator. Therefore, verification using $\mathrm{DFR}_{m}$ allows us to evaluate the model with reduced errors by the simulator uncertainty. The bright band due to melted ice-phase particles is simply simulated using the average dielectric constant of ice and liquid based on Fabry and Szyrmer (1999) at temperatures above $0^{\circ} \mathrm{C}$. The minimum detectable reflectivity is set as 16 and $18 \mathrm{dBZ}$ for KuPR and $\mathrm{KaPR}$, respectively. If the simulated reflectivity is below the minimum detectable reflectivity, the data are regarded as nonhydrometeors. Random noise is added to the simulation using a normal distribution $\mathrm{PDF}$ with a variance of $1 \mathrm{~dB}$ following the receiver power accuracy of the DPR (Iguchi et al. 2018).

Note that brightness temperature $\left(T_{B}\right)$ at the high-frequency band ( $\geq 89 \mathrm{GHz}$ ) clearly depends on the assumption of the particle shape (e.g., Barreyat et al. 2021). However, the difference in $T_{B}$ depending on such particle shape is smaller than the improvement in this study, as shown in section 3 . In addition, the range of diameter for snow particle in the model and the simulator are also different. Specifically, the range of snow diameters in the MSM is defined as 100-20000 $\mu \mathrm{m}$ based on Field et al. (2007), while the range of Liu's type-A snowflake diameter in the I-simulator is defined as 50$10000 \mu \mathrm{m}$ based on Liu (2008). Moreover, although the impact is expected to be limited, there are various uncertainties in the beam shape and cloud inhomogeneity.
Therefore, for more sensitive and quantitative evaluation beyond this study, the simulation results need to be carefully checked and used, taking into account that the simulator is imperfect.

\section{Case study}

In this section, we investigate the heavy-rainfall event that occurred on 7 July 2018. This is a remarkable case of a disaster caused by heavy rain in Japan and is named the Heavy Rain Event of July 2018 (Shimpo et al. 2019). In this heavy rainfall event, the stationary baiu front and Typhoon Prapiroon (T1807) caused heavy rainfall over a wide area of Japan from June 28 to July 8. Many areas, especially in western Japan, experienced heavy rainfall, with many rain gauges recording rainfall 2-4 times higher than the monthly climate in July. Moreover, we investigate also the event of the ocean-effect precipitation by cold surge at 0300 UTC 3 January 2018. The experimental values are compared with the values obtained using MP1702 and MP2003, as described in section $2 \mathrm{a}$. The experimental setting is similar to the operational model at JMA (Japan Meteorological Agency 2019).

We compare the numerical results with the observed values of GPM/GMI and GPM/DPR using the I-simulator described in section $2 \mathrm{~b}$. In these cases, the GPM core satellite observed the precipitation event over Japan during 0035-0039 UTC 7 July 2018, and during 0006-0010 UTC 3 January 2018. The GMI product as reference value is $T b$ in the $\mathrm{L} 1$ product and the DPR product as reference value is measuredZfactor before the correction of attenuation in the L2 product.

Figure 5 shows the GMI's $T_{B}$ at $89 \mathrm{GHzV}$ by comparing the observation with the MP1702 and MP2003 simulations. 

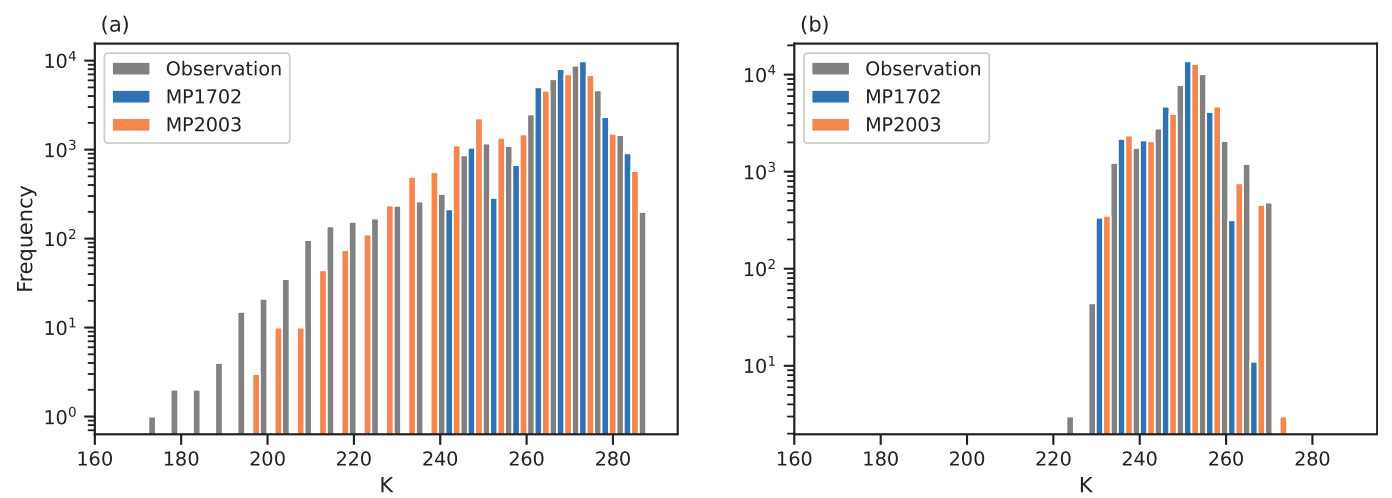

FIG. 6. Histograms of $T_{B}$ at $89 \mathrm{GHzV}$. The gray bars show the observation; the blue bars show the MP1702 simulation; and the orange bars show the MP2003 simulation at (a) 0000 UTC 7 Jul (as in Figs. 5a-c), and at (b) 0600 UTC 3 Jan 2018 (as in Figs. 5d-f).

Figures 5a-c show the case of heavy-rainfall event in summer. In the observation, a low- $T_{B}$ area under $220 \mathrm{~K}$ was widely spread over Japan (Fig. 5a). However, the MP1702 simulation shows that $T_{B}$ is approximately $250 \mathrm{~K}$ all over Japan and failed to simulate the observed low- $T_{B}$ area (Fig. 5b). In contrast, the MP2003 simulation successfully reproduced the low-temperature band of $T_{B}$, suggesting the presence of microwave-scattering ice aloft (Fig. 5c). In the case of winter, Fig. 5d shows that ocean-effect cloud systems by cold surge is observed in the south of Japan. The cloud system in MP2003 simulation is slightly closer to the observation, but not much different from the cloud system in MP1702 simulation (Figs. 5e,f). Figure 6 shows the histograms of $T_{B}$ corresponding to Fig. 5. In the case of summer, Fig. 6a shows that the MP1702 simulation could not reproduce $T_{B}$ lower than $240 \mathrm{~K}$, whereas the MP2003 simulation was closer to the observation as it reproduced $T_{B}$ as low as $200 \mathrm{~K}$. In the case of winter, $T_{B}$ in MP2003 simulation is slightly closer to observed $T_{B}$ than $T_{B}$ in MP1702 simulation over $260 \mathrm{~K}$ (Fig. 6b). However, since the difference between MP1702 and MP2003 in winter is much smaller than that in summer, we focus on the summer case in this study.

Figure 7 compares the observation and simulation values of Ku-band measured reflectivity $Z_{m}(\mathrm{Ku})$ which is not corrected the attenuation at $2500-\mathrm{m}$ altitude. The reflectivity over $40 \mathrm{dBZ}$ is shown in Fig. 7a. The MP1702 simulation reproduced the precipitation accurately but overestimated the reflectivity in the northern area of the map around Tohoku region (Fig. 7b). In the MP2003 simulation, the predicted distribution of $Z_{m}(\mathrm{Ku})$ was not significantly different from that obtained using the MP1702 simulation in the region over $30 \mathrm{~dB} Z$, but the MP2003 simulation captured the observed region under $30 \mathrm{~dB} Z$ more accurately compared to the MP1702 simulation (Fig. 7c). It is noteworthy that the southern edge of the precipitation area in the MP2003 simulation is slightly larger and closer to observation than that in the MP1702 simulation.

Figure 8 is the vertical cross section of KuPR on the position shown by the solid black lines in Fig. 7. Figure 8 a shows the $Z_{m}$ $\mathrm{Ku}$ ) observation, which is masked below an altitude of approximately $2000 \mathrm{~m}$ because data at lower levels are contaminated by surface clutter (known as using the binClutterFreeBottom in the DPR L2-product; Kubota et al. 2016). Figure $8 b$ shows the simulated $Z_{m}(\mathrm{Ku})$ values in the MP1702 simulation. The simulated reflectivity is smaller than the minimum detectable reflectivity of $16 \mathrm{dBZ}$ in the upper atmosphere above $6000 \mathrm{~m}$. In crosssection $\mathrm{B}$, the reflectivity of the MP1702 simulation is stronger than the observation in the $136^{\circ}-140^{\circ} \mathrm{E}$ region. In both observations and simulations, the bright band exists around an
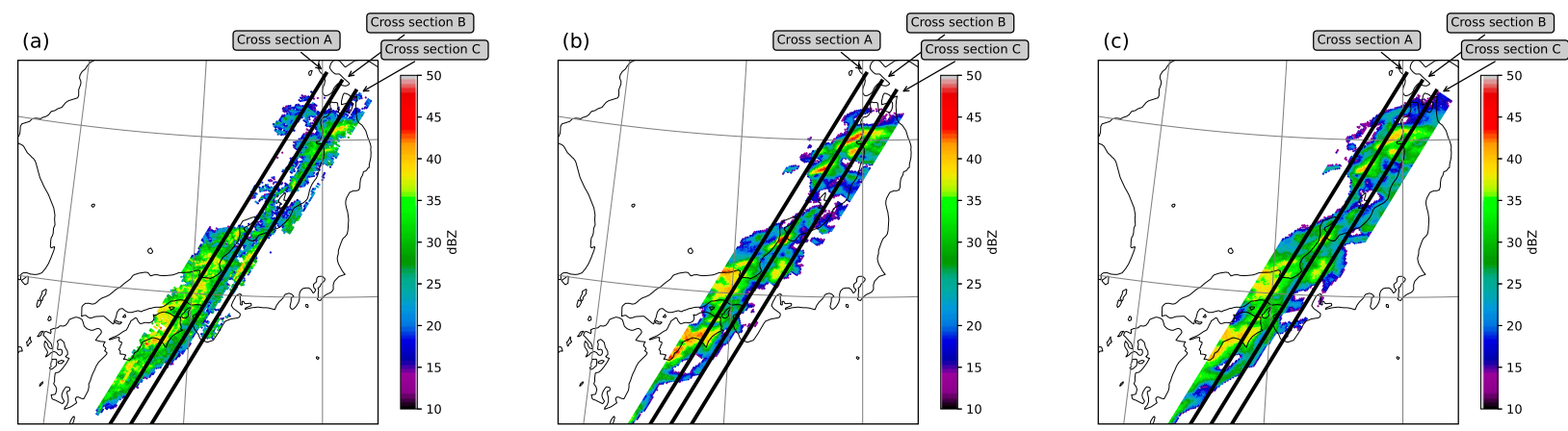

FIG. 7. As in Figs. 5a-c, but with the Ku-band reflectivity $Z_{m}(\mathrm{Ku})$ at the altitude of $2500 \mathrm{~m}$ of the (a) KuPR observation, (b) MP1702 simulation, and (c) MP2003 simulation. 

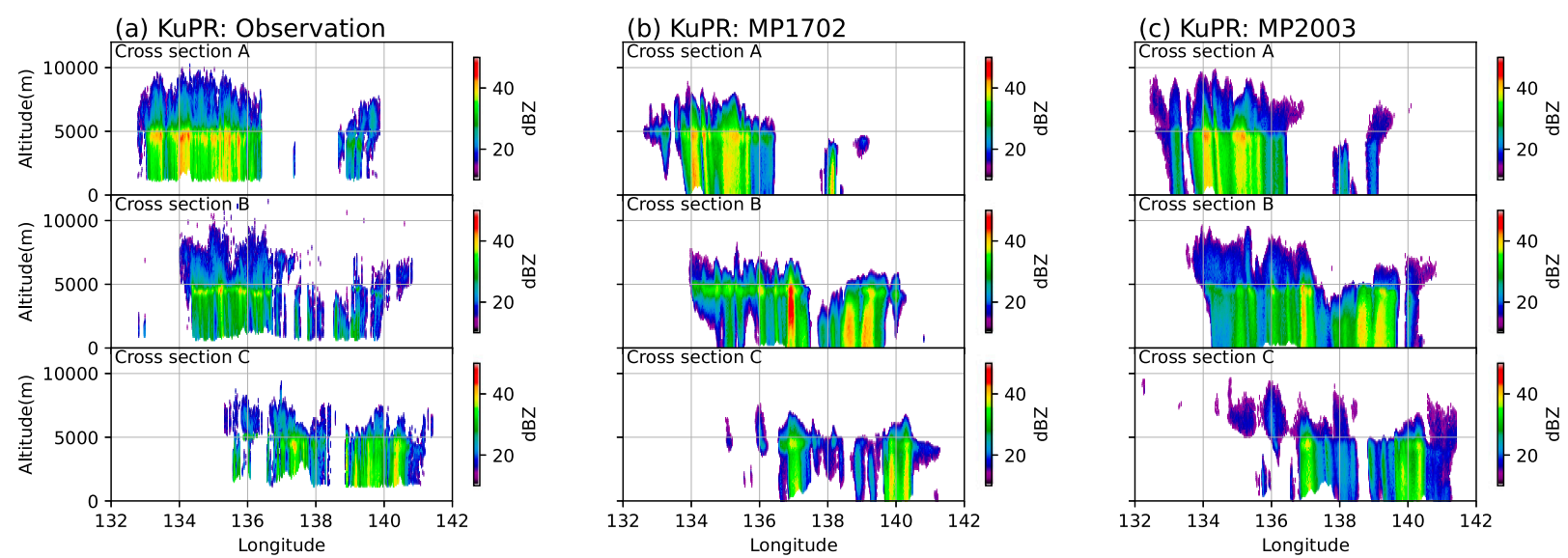

(d) KaPR: Observation

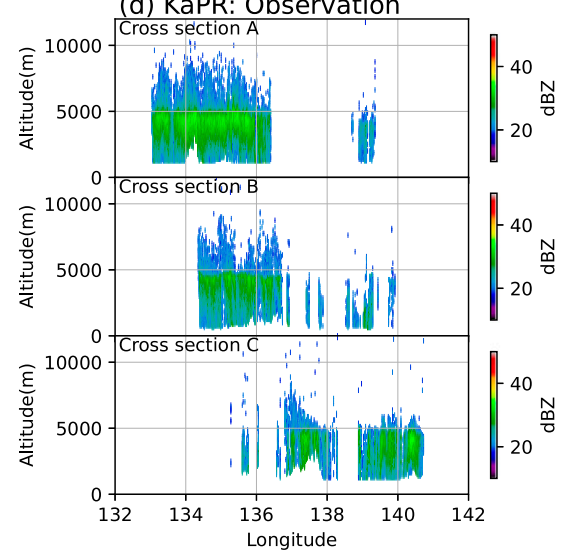

(e) KaPR: MP1702
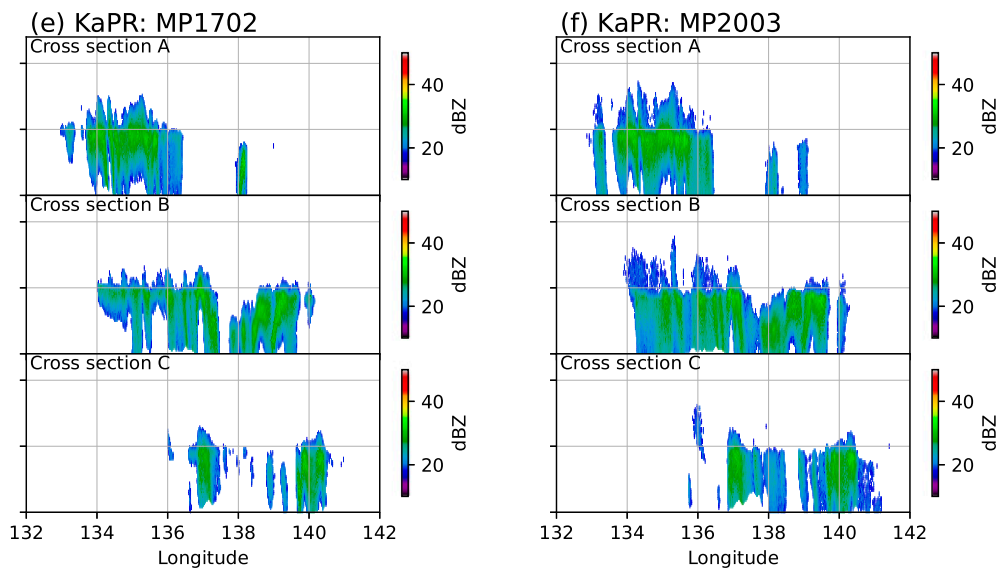

(g) DFR: Observation
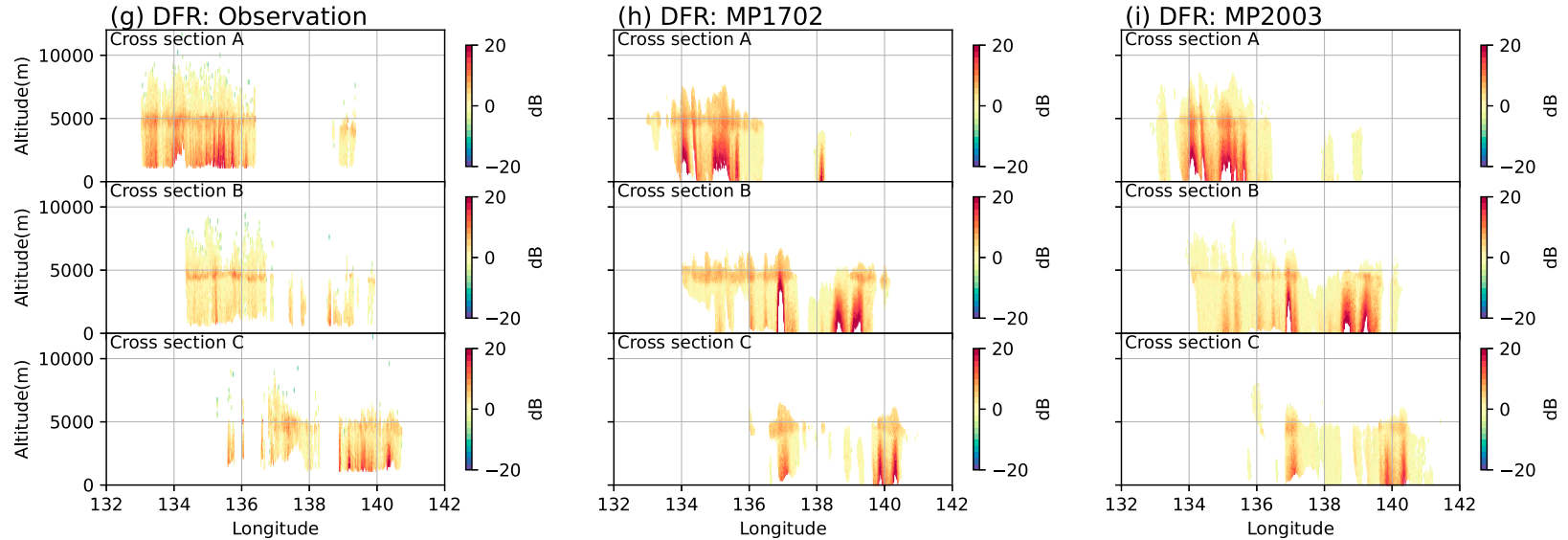

FIG. 8. Vertical cross section of (top) $Z_{m}(\mathrm{Ku})$, (middle) $Z_{m}(\mathrm{Ka})$, and (bottom) DFR ${ }_{m}$ in the position shown in Fig. 7. (a),(d),(g) Observed reflectivity; (b),(e),(h) simulated reflectivity in the MP1702 simulation; and (c),(f),(i) simulated reflectivity in the MP2003 simulation.

altitude of $5000 \mathrm{~m}$. In the lower atmosphere, except in areas of high reflectivity (over $35 \mathrm{dBZ}$ ), the simulated reflectivity is weaker than the observed reflectivity. In some areas, such as around $134^{\circ} \mathrm{E}$ of cross-section $\mathrm{B}$, the simulated reflectivity is smaller than the minimum detectable reflectivity. Figures $8 \mathrm{c}$ shows the vertical distribution of the KuPR simulation in the MP2003 simulation. The two abovementioned biases in the MP1702 simulation are improved in MP2003; the reflectivity at altitudes of both above $5000 \mathrm{~m}$ and under $4000 \mathrm{~m}$ increased and became closer to the observed reflectivity in the MP2003 simulation. Figure 9 shows the contour frequency altitude diagrams (CFADs: Yuter and Houze 1995) for KuPR on the path of DPR shown in Fig. 7. The CFADs median for KuPR shows that the MP1702 simulation has an excess of reflectivity over the observation around the altitude of $5000 \mathrm{~m}$ and the reflectivity decreases rapidly to below $25 \mathrm{dBZ}$ at altitudes of around $3000-4000 \mathrm{~m}$ (Fig. 9b). The median of the CFADs in the MP2003 simulation indicates that the reflectivity remains 
(a) KuPR: Observation

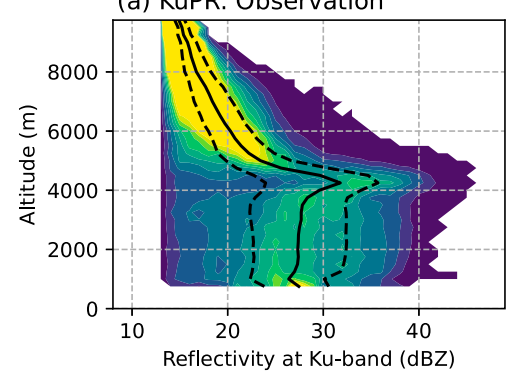

(d) KaPR: Observation

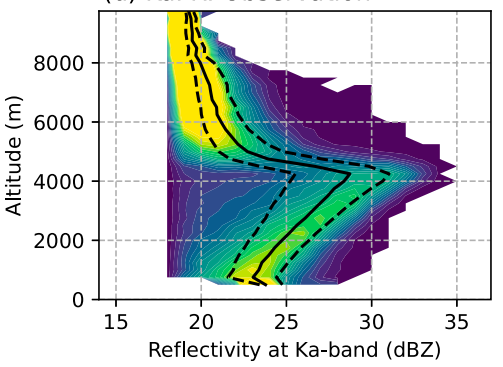

(g) DFR: Observation

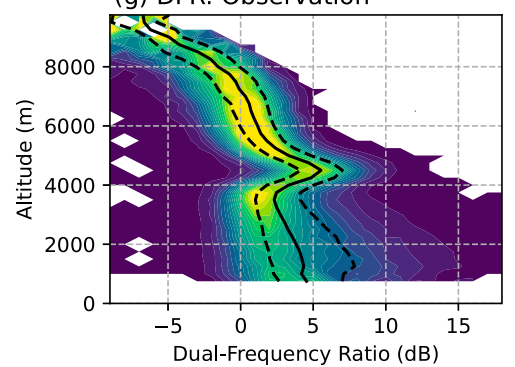

(b) KuPR: MP1702

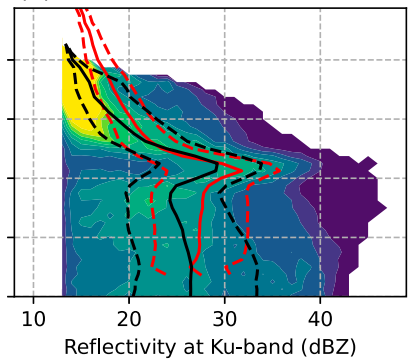

(e) KaPR: MP1702

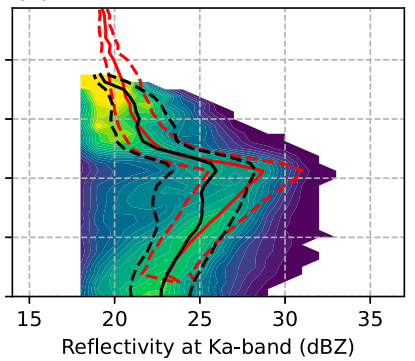

(h) DFR: MP1702

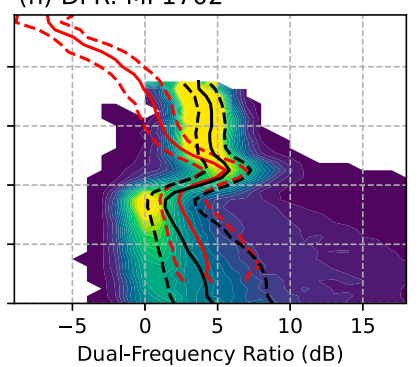

(c) KuPR: MP2003

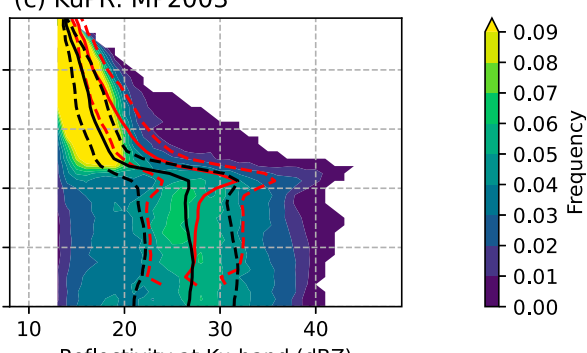

Reflectivity at Ku-band (dBZ)

(f) KaPR: MP2003

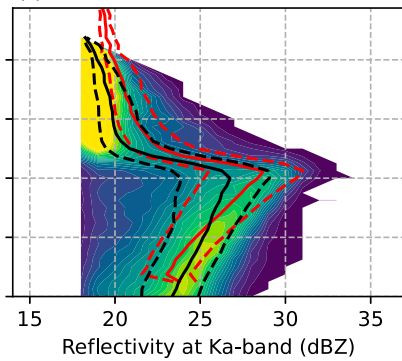

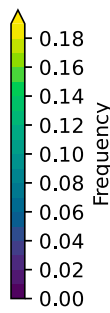

(i) DFR: MP2003

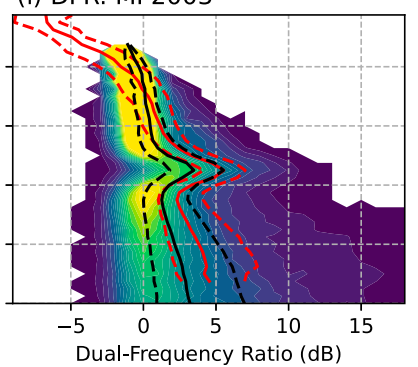

$-0.18$

0.16

0.14

-0.12 ठे

$-0.10 \frac{\mathrm{g}}{\mathrm{g}}$

-0.08 g

0.06

$-0.04$

$-0.02$

0.00

FIG. 9. CFADs of (top) $Z_{m}(\mathrm{Ku})$, (middle) $Z_{m}$ (Ka), and (bottom) DFR ${ }_{m}$ in the region shown in Fig. 7. (a),(d),(g) Observed reflectivity; (b),(e),(h) simulated reflectivity in the MP1702 simulation; and (c),(f),(i) simulated reflectivity in MP2003 simulation. The solid line shows the median and dashed lines show the 25 th and 75 th percentiles. The red lines show the percentiles of observation corresponding to the element.

approximately the same $(27.5 \mathrm{dBZ})$ even below the altitude of $4000 \mathrm{~m}$ (Fig. 9c).

Figure 8d shows the vertical cross sections of the observed KaPR, where the clutter in low layers below the altitude of $2000 \mathrm{~m}$ is masked, as in KuPR. Figure 8e shows the simulated results of KaPR for the MP1702 simulation. In cross-section B, in particular, the reflectivity below an altitude of $5000 \mathrm{~m}$ at longitude $134^{\circ}-137^{\circ} \mathrm{E}$ underestimates the simulated KaPR. This bias is reduced in the MP2003 simulation (Fig. 8f). In the lower atmosphere, where the reflectivity of KuPR is strong around the melting layer $\left(134^{\circ}-135^{\circ} \mathrm{E}\right.$ in cross section $\mathrm{A}$; Fig. 8a), the reflectivity of KaPR is weaker because of rainfall attenuation. Figures $9 \mathrm{~d}-\mathrm{f}$, which is the same as Figs. 9a-c but for KaPR, shows the CFADs. Figure 9e indicates that the CFAD median in the MP1702 simulation decreased to approximately $25 \mathrm{dBZ}$ at an altitude of approximately 3000$4000 \mathrm{~m}$, which is not seen in the observation (Fig. 9d). In Fig. 9f, the median of the CFADs in the MP2003 simulation is closer to the observation compared to the MP1702 simulation, though still weaker than the observation. The reflectivity of the Kaband at altitudes of $4000-6000 \mathrm{~m}$ is well represented compared to the Ku-band in MP2003, suggesting that there is a large error in the brightband simulation.

GPM/DPR observation is advantageous for investigating the characteristics of hydrometeors using simultaneous observations of the dual frequencies of radar signals ( $\mathrm{Ku}$ and $\mathrm{Ka}$ bands). $\mathrm{DFR}_{m}$ in Eq. (11) is the difference ratio of $\mathrm{Ku}$ and Ka-band reflectivities, and its magnitude depends on the type and size of hydrometeor particles. Figures $8 \mathrm{~g}-\mathrm{i}$ compares the observed $\mathrm{DFR}_{m}$ (Fig. 8g) with the simulated DFR $_{m}$ for MP1702 (Fig. 8h) and MP2003 (Fig. 8i). Both the observed and simulated $\mathrm{DFR}_{m}$ are higher in the lower levels of precipitation, where $Z_{m}(\mathrm{Ku})$ is greater than $35 \mathrm{~dB} Z$ because of the greater KaPR attenuation. In the layer above the bright band, the $\mathrm{DFR}_{m}$ of MP1702 simulation is higher than that of the observation and that of MP2003 is much closer to the observation. The MP1702 bright band is wider than the observed and that of MP2003 is comparable to the observed. In the CFADs of the $\mathrm{DFR}_{m}$ (Figs. 9g-i), MP1702 has a large bias above the altitude of $6000 \mathrm{~m}$ but the bias in MP2003 simulation is reduced to values comparable to the observation. Below the altitude of $4000 \mathrm{~m}$, the $\mathrm{DFR}_{m}$ of 


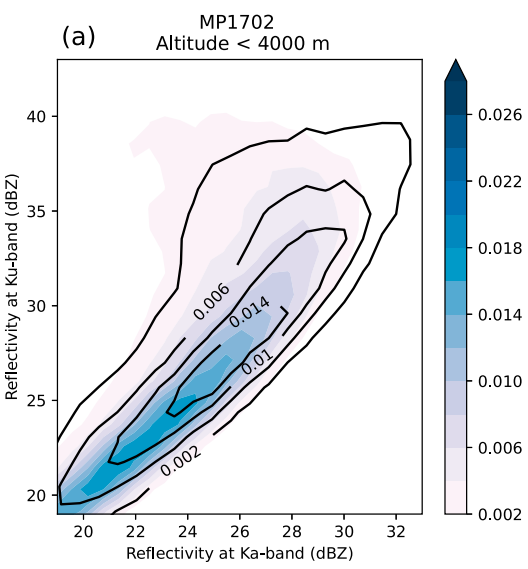

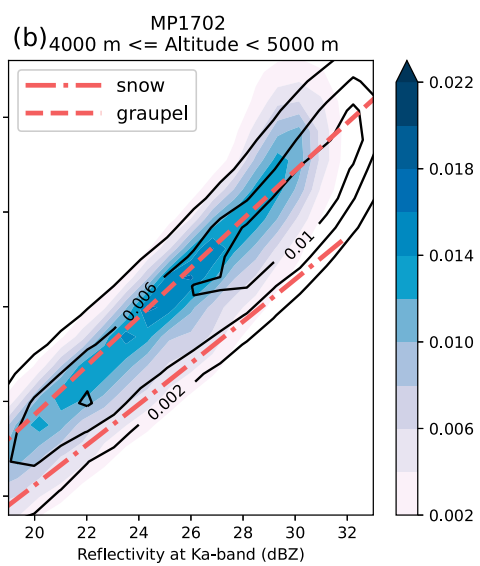

\section{MP1702
(c) $\quad$ Altitude $>=5000 \mathrm{~m}$}

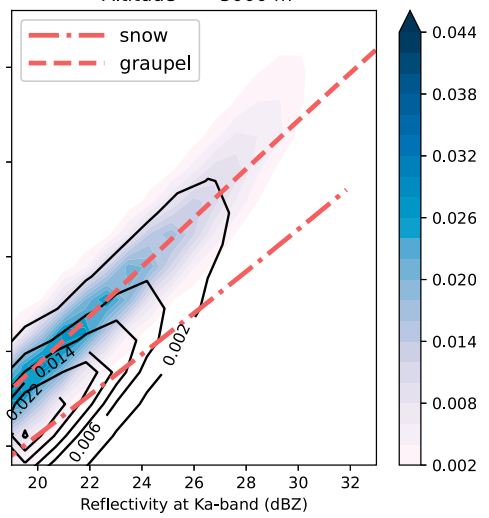

MP2003

(e) $4000 \mathrm{~m}<=$ Altitude $<5000 \mathrm{~m}$

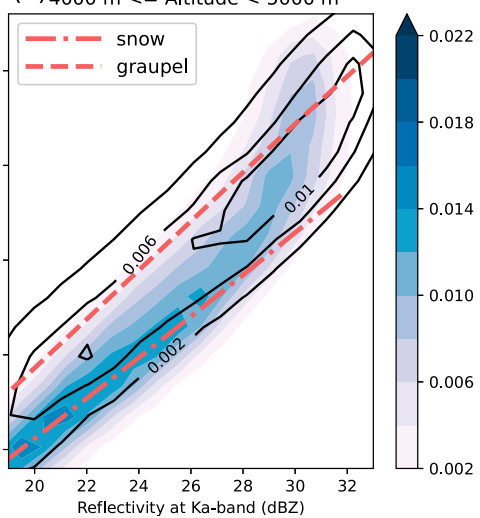

MP2003
(f) $\quad$ Altitude $>=5000 \mathrm{~m}$

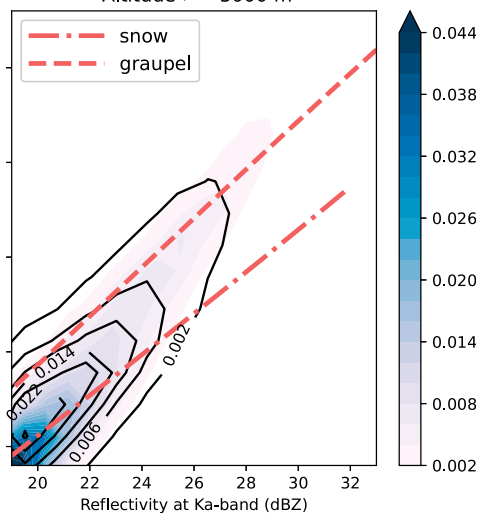

FIG. 10. 2D histogram of the reflectivity of the Ka- and Ku-bands. The solid lines show the DPR observation, and the shaded area is given by (top) MP1702 and (bottom) MP2003: (a),(d) altitude $<4000 \mathrm{~m}$; (b),(e) $4000 \leq$ altitude $<5000 \mathrm{~m}$; and (c), (f) altitude $\geq 5000 \mathrm{~m}$. The dashed line is the $Z_{m}(\mathrm{Ka})-Z_{m}(\mathrm{Ku})$ relationship of the model's graupel and the dash-dotted line is $Z_{m}(\mathrm{Ka})-Z_{m}(\mathrm{Ku})$ relationship of the model's snowflake.

both experiments is not significantly different from the observation.

Figure 10 compares two-dimensional joint histograms showing the frequency distribution of $Z_{m}(\mathrm{Ku})$ and $Z_{m}(\mathrm{Ka})$. Figure 10a shows the frequency distributions for the liquid phase at altitudes below $4000 \mathrm{~m}$, Fig. 10b for the mixed phase at altitudes between 4000 and $5000 \mathrm{~m}$, and Fig. 10c for the ice phase at altitudes above $5000 \mathrm{~m}$. The solid line shows the distribution of observation, and the shades show the result of the MP1702 simulation. The dashed line in Fig. 10 represents the $Z_{m}(\mathrm{Ka})$ $Z_{m}(\mathrm{Ku})$ relationship for graupel, obtained from the scattering calculation, and the dot-dash line represents the $Z_{m}(\mathrm{Ka})$ $Z_{m}(\mathrm{Ku})$ relationship for snowflakes (Liu 2008). In the liquid phase, the observed and simulated frequency distributions are similar but the simulated frequency peak is located at a weaker portion in both $Z_{m}(\mathrm{Ka})$ and $Z_{m}(\mathrm{Ku})$ (around $23 \mathrm{dBZ}$ for both reflectivity) than in the observation (around $26 \mathrm{dBZ}$ ). In the mixed and ice phases, the position of the simulation peak is significantly different between the observation and MP1702 simulation. Figures 10d-f show the result of the MP2003 simulation as in Figs. 10a-c. In the liquid phase, the frequency peak position is much closer to the observation peak (Fig. 10d). In the mixed phase, $Z_{m}(\mathrm{Ku})$ is smaller than the observation and the error is still large (Fig. 10e). However, in the ice phase, the frequency peak is closer to the observation (Fig. 10f). The peaks for the observation and MP2003 simulation are close to the $Z_{m}(\mathrm{Ka})-$ $Z_{m}(\mathrm{Ku})$ relationship for snowflakes, indicating that snow was dominant here. In both the observation and MP2003 simulation, as the $Z_{m}(\mathrm{Ka})$ and $Z_{m}(\mathrm{Ku})$ become stronger, the frequency distribution shifts from the $Z_{m}(\mathrm{Ka})-Z_{m}(\mathrm{Ku})$ relationship of snow to that of graupel. These results indicate that the difference between observation and simulation is smaller for MP2003 than for MP1702. In other words, not only the reflectivity because of rain but also because of snow and graupel for the MP2003 simulation are improved compared to the MP1702 simulation.

Figure 11 shows the vertical distributions of the mixing ratio of hydrometeors of the predicted categories, their tendencies, and the tendency of potential temperature. This vertical distribution is calculated by averaging the predicted values along the DPR path at each altitude at 0700 UTC 7 July 2018. The term $d q_{x} /\left.d t\right|_{\mathrm{MP}}$ is the tendency of the mixing ratio of category $x$ because of the cloud microphysics process, $d \theta /\left.d t\right|_{\mathrm{MP}}$ is the 

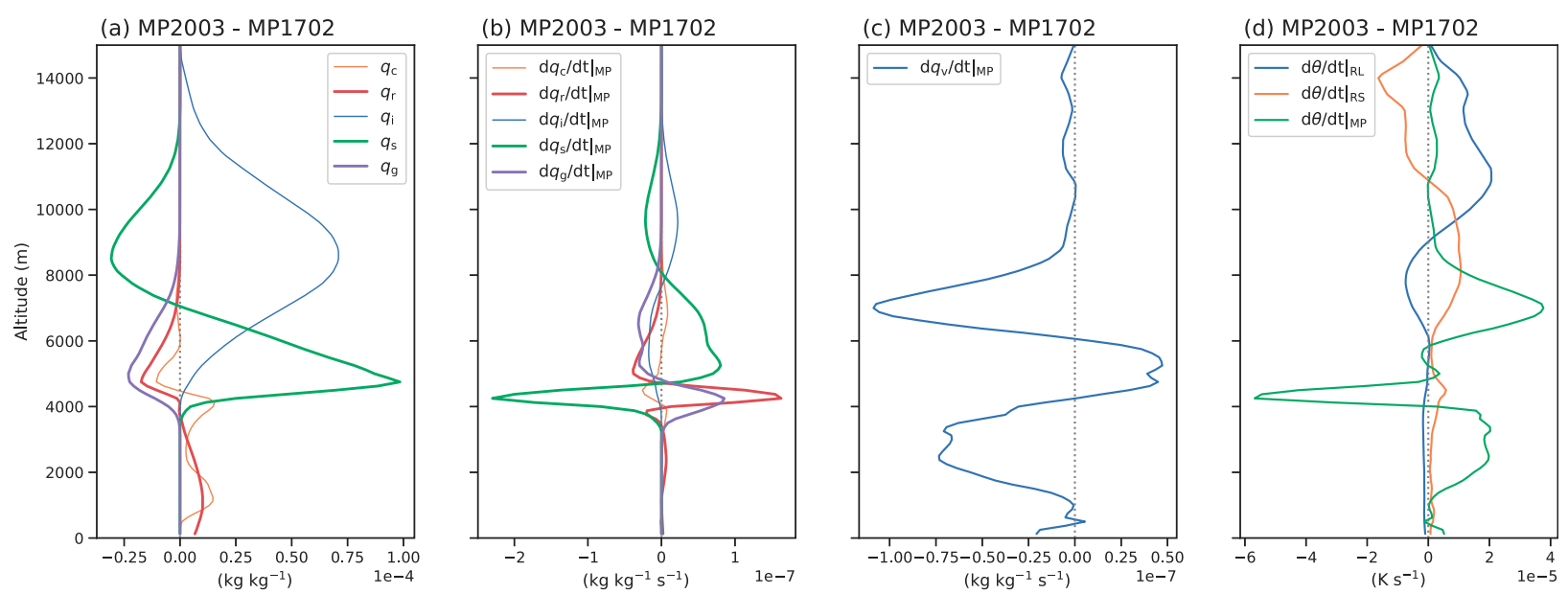

FIG. 11. Vertical distribution of average hydrometeors. (a) Mixing ratios of hydrometeors and (b)-(d) 1-h averaged tendencies of the MP2003 simulation minus the MP1702 simulation. Differences in tendencies for (b) hydrometeors and (c) water vapor from cloud microphysics and (d) potential temperature from shortwave radiation (RS), longwave radiation (RL), and cloud microphysics (MP).

tendency of potential temperature using the cloud microphysics process, and $d \theta /\left.d t\right|_{\mathrm{RS}}\left(d \theta /\left.d t\right|_{\mathrm{RL}}\right)$ is the tendency of potential temperature because of the shortwave (longwave) radiative heating. Figure 11 shows the result of the MP2003 simulation minus the result of the MP1702 simulation. The cloud ice mixing ratio increases, the graupel decreases at altitudes above $5000 \mathrm{~m}$, and the rain increases in the lower levels in the MP2003 simulation (Fig. 11a). As shown in Fig. 11c, the water vapor decreases at altitudes of around 6000-8000 and $3000-4000 \mathrm{~m}$ in the MP2003 simulation, which is partly because of the increase in snow diffusion growth and decrease in rain evaporation. $d \theta /\left.d t\right|_{\mathrm{MP}}$ of the MP2003 simulation, calculated from the diabatic heating of latent heat release of the cloud physical processes, is larger than that of the MP1702 simulation at altitudes below $4000 \mathrm{~m}$ because of the decrease in rain evaporation and lower than that at the MP1702 simulation in the 4000-5000-m layer because of the increase in the amount of melting snow (Figs. 11b,d). The increase in ice clouds increases radiative heating in the upper troposphere in the 10000 $11000-\mathrm{m}$ layer, increasing the potential temperature tendency (Fig. 11d).

\section{A kinematic model analysis}

The previous section revealed that the MP1702 simulation scheme has the following three problems:

- The scattering signal of microwave $T_{B}$ at $89 \mathrm{GHz}$ is weaker than the observation, and the reflectivity is also weaker than observation aloft the melting layer.

- In the mixed or ice phases above the melting layer at 4000$5000 \mathrm{~m}$, the $\mathrm{DFR}_{m}$ is larger than the observation.

- In the liquid phase at altitudes lower than $4000 \mathrm{~m}$, the reflectivity is weaker than the observation.

In this section, we clarify the causes of these problems and see how they are improved by introducing MP2003. We use a single-column kinematic model, Kinematic Driver Model
(KiD; Shipway and Hill 2012), to investigate the effect of the changes in the cloud microphysics scheme. We adopt the deep convection and warm rain cases implemented in KiD. See Shipway and Hill (2012) for details of the design of these test cases. Table 2 summarizes the parameter settings of the cloud microphysics process for the experiments performed in this section.

\section{a. Positive bias of brightness temperature}

The low scattering of ice clouds in microwave radiation in the MP1702 simulation causes the bias in $T_{B}$ at $89-\mathrm{GHzV}$ band. The low scattering of ice clouds is because of the small amount of mass concentration of ice clouds. One reason for the small mass concentration of ice clouds is the fast conversion efficiency of ice clouds to snow because $f_{\mathrm{AGG}}$ is dominant in $\mathrm{QCN}_{i s}$, as shown in Fig. 4. Another reason is that the terminal velocity of cloud ice in the MP1702 simulation is set closer to graupel than ice crystals, as shown in previous studies (Ferrier et al. 1995; Mitchell 1996) (see Table 1 and Fig. 2).

Figure 12 shows the time evolutions of vertical profiles for each hydrometeor category for the case of the deep clouds simulated by KiD. In the MP1702 simulation (Fig. 12a), almost

TABLE 2. Experimental setting.

\begin{tabular}{lc}
\hline \multicolumn{1}{c}{ Expt } & \multicolumn{1}{c}{ Details } \\
\hline MP1702 & $\begin{array}{c}\text { Operation setting in MSM until March 2020 } \\
\text { (Japan Meteorological Agency 2019) }\end{array}$ \\
MP1702F & As in MP1702, but for $f_{\text {AGG }}=0$ \\
MP1702FVA & $\begin{array}{c}\text { As in MP1702F, but the terminal velocity of } \\
\text { cloud ice, QCL }\end{array}, E_{i s}$, and $q_{c 0}$ are modified \\
(see section 2) & As in MP1702FVA, but for PSD of rain \\
uP2003 & fred in MP; operation setting in MSM \\
& from March 2020 \\
\hline
\end{tabular}



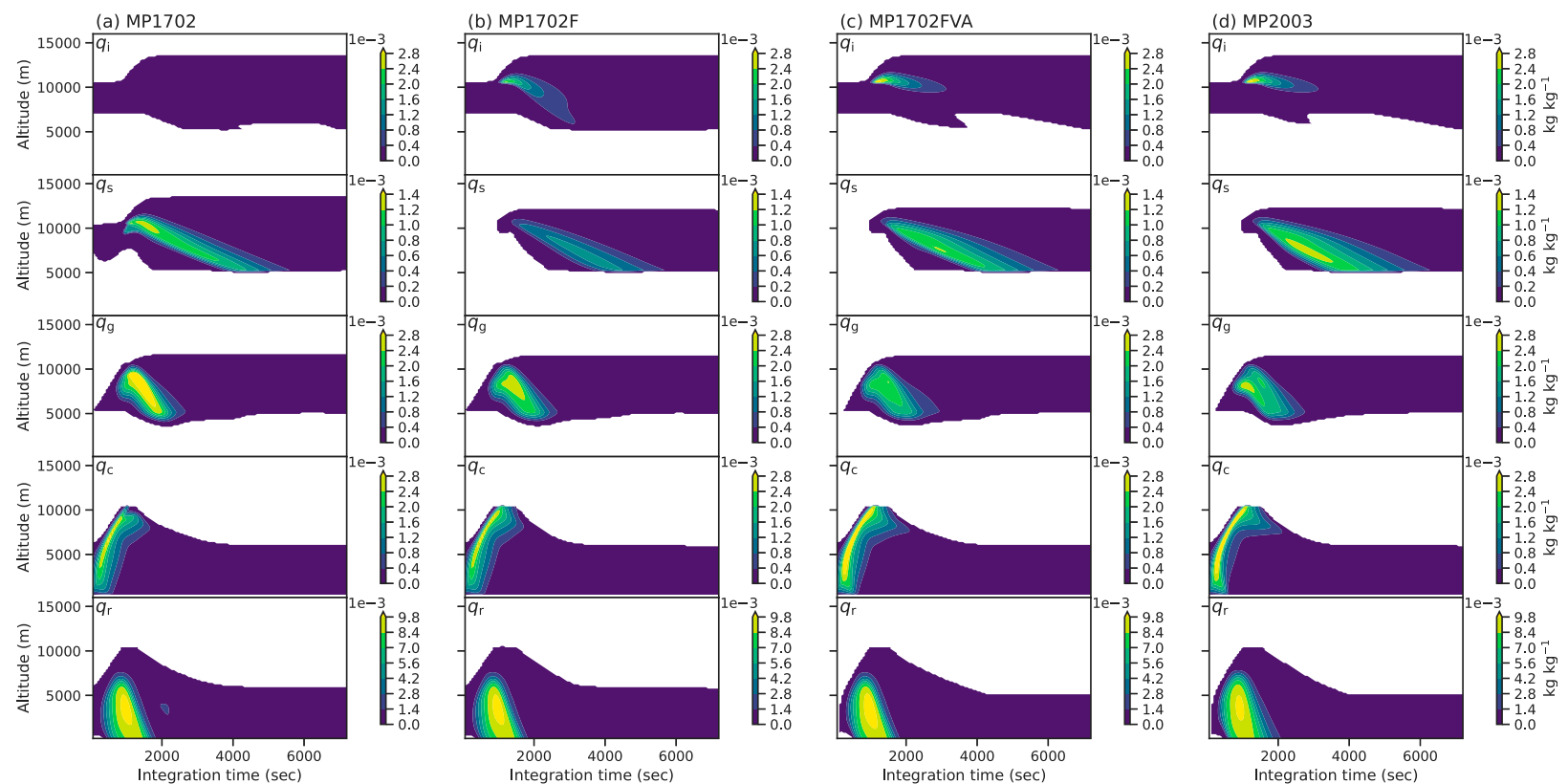

FIG. 12. Vertical profiles of hydrometeors predicted by KiD: (from top to bottom) cloud ice, snow, graupel, cloud water, and rain. Time evolutions of mixing ratio obtained from the (a) MP1702, (b) MP1702F, (c) MP1702FVA, and (d) MP2003 simulations.

all ice clouds are converted to snow as soon as ice nucleation occurs and the remaining ice falls at a high rate; thus, there is almost no ice in the upper layer. In the MP1702F simulation (Fig. 12b), the conversion from ice to snow is suppressed by setting $f_{\text {AGG }}=0$ (Table 2 ). The result shows that the ice clouds remain in the upper layer. In the MP1702FVA simulation (Fig. 12c), the terminal velocity of ice, collection of ice to snow, and autoconversion of cloud to rain were modified in addition to the changes in MP1702F simulation (Table 2), allowing ice clouds to stay in the upper layers. In the MP2003 simulation (Fig. 12d), the PSD of rain was modified in addition to the changes in MP1702FVA simulation. Consequently, there is greater increase in cloud ice and snow in the upper layers. The results indicate that the improvement in $T_{B}$ in the MP2003 simulation is because of the modification of $f_{\mathrm{AGG}}$ and terminal velocity.

\section{b. Overestimated reflectivity above melting layer}

The overestimation of $\mathrm{DFR}_{m}$ in MP1702 above the melting layer is because of the overprediction of graupel particles. Figure 13 shows the time-averaged vertical distribution of the mixing ratio of hydrometeors, production terms of snow, and graupel in the single-column kinematic model during the integration time of $0-7200 \mathrm{~s}$. Note that the melting process is not shown. The production terms shown in Fig. 13 are defined as follows: $\mathrm{QCN}_{x(y) z}$ is the autoconversion process from category $x$ (and category $y$ ) to category $z, \mathrm{QCL}_{x y}$ is the collection process of $x$ by $y, \mathrm{QCL}_{x y z}$ is the production rate of category $z$
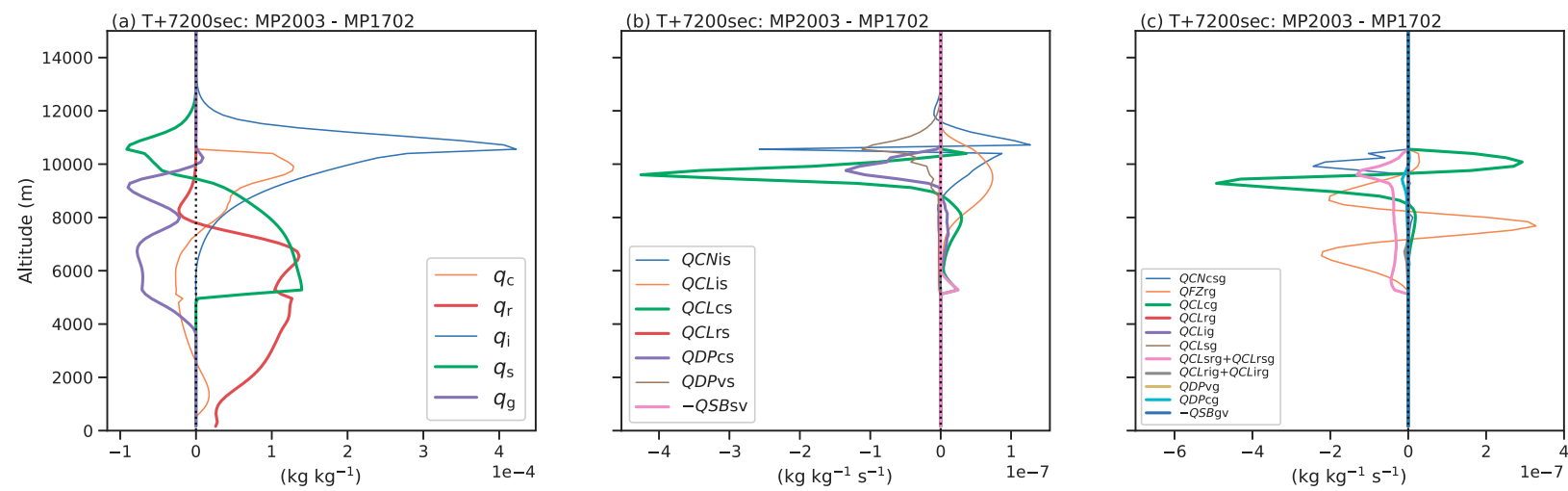

FIG. 13. Time-averaged vertical profiles of mixing ratio and tendency during $(T+0)$ and $(T+7200) \mathrm{s}$ by KiD. This case is the test case of deep convection. The solid lines show (a) the mixing ratio profiles of the MP2003 simulation minus the MP1702 simulation and (b),(c) the tendencies of the MP2003 simulation minus the MP1702 simulation. 

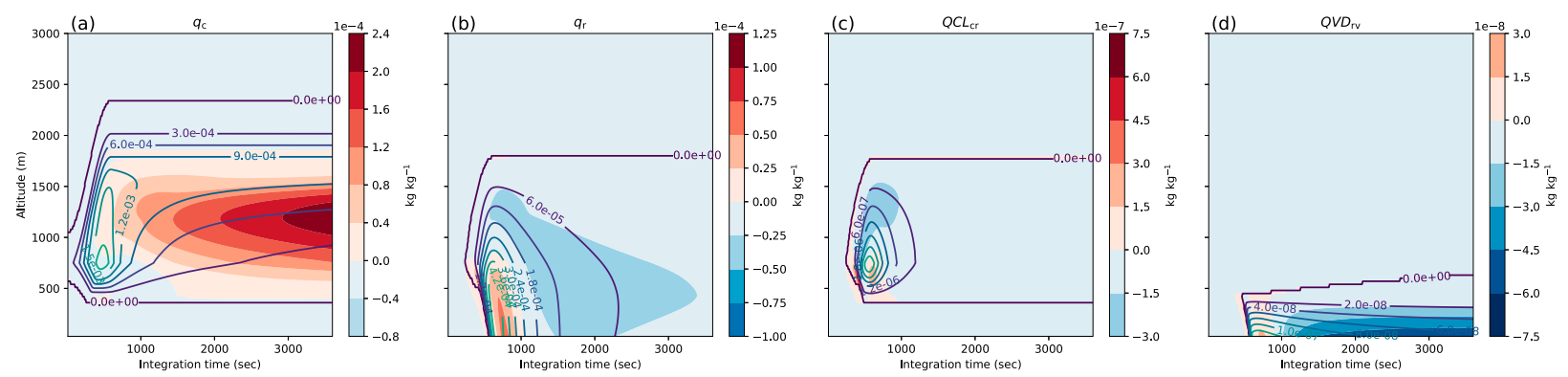

FIG. 14. Warm rain case of KiD. The contour shows (a) $q_{c}$, (b) $q_{r}$, (c) $\mathrm{QCL}_{c r}$, and (d) $\mathrm{QVD}_{r v}$ in the MP1702FVA simulation. The shading shows the MP2003 simulation minus the MP1702FVA simulation.

because of the collection process of $x$ by $y, \mathrm{QVD}_{x v}$ is the evaporation from $x, \mathrm{QDP}_{x y}$ is the deposition from $x$ to $y, \mathrm{QSB}_{x v}$ is the sublimination from $x$, and $\mathrm{QFZ}_{x y}$ is the freezing process from $x$ to $y$. MP1702 and MP2003 simulation experiments are compared in Fig. 13.

First, in MP2003, cloud ice is maintained and grows in the upper layers because of the slower terminal velocity of cloud ice and the elimination of $f_{\mathrm{AGG}}$, and its conversion to snow is suppressed in Eq. (5). Regarding the production term, collection unrelated to cloud ice and diffusional growth leading to snow growth are also suppressed. However, the time averages of $\mathrm{QCL}_{i s}$ and $\mathrm{QCN}_{i s}$ increased because of cloud ice in the upper layers. The vertical distribution of graupel in the layer between 8000 and $12000 \mathrm{~m}$ shows that $\mathrm{QCN}_{c s g}$ and $\mathrm{QCL}_{s r g}+\mathrm{QCL}_{r s g}$ decreased with the decrease in snow as a source in MP2003. Graupel production is also delayed, decreasing $\mathrm{QCL}_{c g}$. Incidentally, the increase in $\mathrm{QCL}_{c g}$ around $12000 \mathrm{~m}$ compensates for the decrease in $\mathrm{QCN}_{c s g}$.

Next, for rain and graupel, $\mathrm{QFZ}_{r g}$ is reduced and graupel is suppressed. Since QFZ $_{r g}$ depends on the slope parameter using the formulation of Bigg (1953), the difference in the freezing amount from rain to graupel is because of the difference in PSD of rain. Phenomenologically, using the MP PSD implies that the freezing of small rain particles is suppressed more than that when using the AB PSD. Consequently, below $10000 \mathrm{~m}$, graupel decreases, $\mathrm{QCL}_{c s g}$ and $\mathrm{QCL}_{r s g}+\mathrm{QCL}_{s r g}$ are further suppressed, and snow increases in MP2003. From the above, MP2003 has less predicted graupel amounts and more predicted snow amounts than MP1702. Therefore, the change in the predicted amount of graupel and snow improved the $Z_{m}$ $(\mathrm{Ka})-Z_{m}(\mathrm{Ku})$ relationship.

\section{c. Underestimated reflectivity at lower layer}

In MP1702, even outside the strong precipitation area, the reflectivity is smaller in the lower layers of the predicted weak precipitation area because of the small amount of predicted $q_{r}$. Specifically, when $q_{r}$ is small, the reflectivity of MP1702 is smaller because the $\mathrm{AB}$ scheme has much more small particles than the classical negative exponential distribution (MP scheme). Figure 14 shows the results of the single-column kinematic model in the case of warm rain simulated by KiD. The experiments compared are MP1702FVA and MP2003, showing the difference between the $\mathrm{AB}$ and MP schemes. When $q_{r}$ is small, the magnitude of the production term for collection and evaporation in MP2003 is smaller than that in MP1702FVA (Figs. 14b-d). Consequently, the precipitation peak at $800 \mathrm{~s}$ of integration time is increased, and the evaporation after $1000 \mathrm{~s}$ is suppressed (Fig. 14d). This change in the simulated rain particles improved the reflectivity in the lower layers.

\section{Impacts on the numerical weather forecasts}

An assimilation-forecast cycle experiment was performed to verify the impact on forecasts using the JMA mesoscale NWP system by changing the cloud microphysics scheme. The NWP model setup is the same as in the case study. The forecasting range covered by the statistical verification is $39 \mathrm{~h}$. The initial time of forecast is created every $3 \mathrm{~h}$. The NWP model runs eight times per day. The experimental period was selected for the summer experiment from 18 June to 23 July 2018, and the winter experiment from 23 December 2017 to 27 January 2018. In the experiment, the cloud microphysics scheme of the forecast model used in the data assimilation system was changed from MP1702 to MP2003. The data assimilation method in the mesoscale NWP system is the four-dimensional variational method with strong constraints on the forecast model. If the data assimilation system is not updated simultaneously, there is a high risk of missing the error drift of the forecast model. Therefore, it is critical to maintain consistency between the internal models of the assimilation system and the forecast model.

First, the precipitation verification results are presented. The precipitation verification is based on the 3 -h integrated precipitation averaged over $20 \mathrm{~km}$ of the verification grid to compare observations and forecast with same resolution. The reference value is the Radar/Rain-gauge-Analyzed Precipitation (R/A: Nagata 2011) of JMA. The R/A is the two-dimensional precipitation product observed by ground-based radar and corrected by rain gauge observations in Japan. The bias score and equitable threat score (ETS) were obtained for the forecast time from 3 to $39 \mathrm{~h}$. The bias score greater than 1.0 indicates overprediction, and the bias score less than 1.0 indicates underprediction. The ETS for perfect forecast indicates 1.0. Figure 15a shows the bias score for the MP1702 simulation (blue) and MP2003 simulation (orange), and Fig. 15b shows the change in the bias score (the MP2003 simulation minus the MP1702 simulation) in summer. The precipitation forecasts with a threshold 
(a)

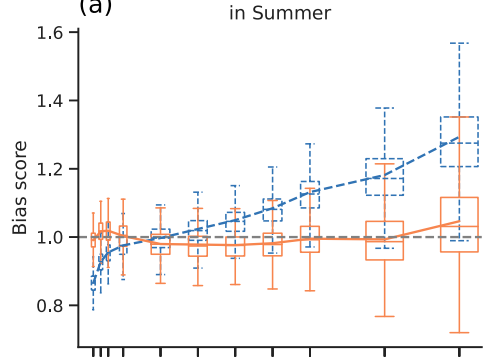

(d)

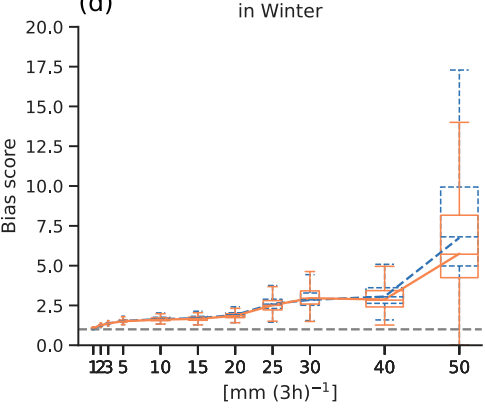

(b)

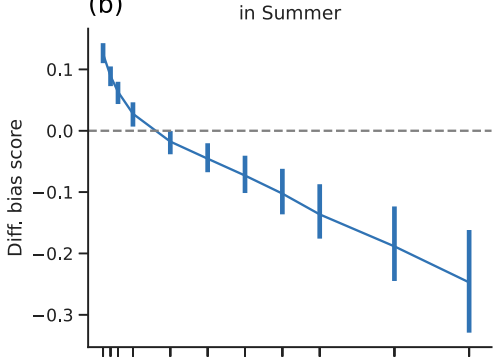

(e)

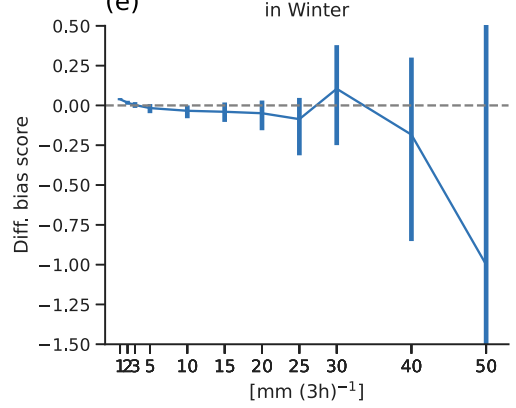

(c)

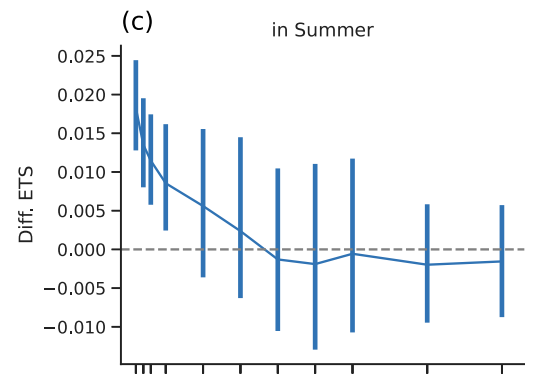

(f)

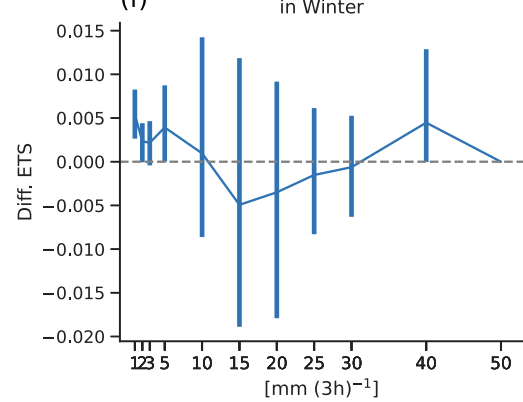

FIG. 15. Scores of precipitation forecast. (a),(d) Bias score of the MP1702 simulation (blue) and MP2003 simulation (orange). (b),(e) Bias score of the MP2003 simulation minus the MP1702 simulation. (c),(f) ETS of the MP2003 simulation minus the MP1702 simulation. (top) Scores in the summer experiment and (bottom) scores in the winter experiment. (a),(d) The box-and-whisker plots show the 0th, 25th, 50th, 75th, and 100th percentiles. (b),(c),(e),(f) The error bars show a $95 \%$ confidence interval calculated using the bootstrap method.

of less than $10 \mathrm{~mm}(3 \mathrm{~h})^{-1}$ increased from the MP1702 simulation to the MP2003 simulation, whereas the precipitation forecasts with a threshold of more than $10 \mathrm{~mm}(3 \mathrm{~h})^{-1}$ decreased. Summer bias scores improved significantly in the wide range of precipitation intensity of more than $10 \mathrm{~mm}(3 \mathrm{~h})^{-1}$. Figure $15 \mathrm{c}$ shows the difference in ETS between the MP1702 and MP2003 simulations, where positive values mean improvement for the MP2003 simulation. The ETS shows a significant improvement in precipitation predictions below $10 \mathrm{~mm}(3 \mathrm{~h})^{-1}$. The bottom panels of Fig. 15 show the winter scores. The winter bias scores are overforecasted (Fig. 15d), but the ETS of the threshold be-

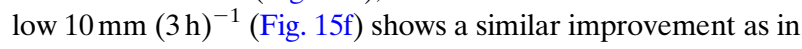
the summer experiment.

Next, we compare the model with the sonde observations in Japan. Figure 16 shows the validation results of the 24-h forecast. Figure 16 shows the temperature validation results, where the negative biases at $200-250 \mathrm{hPa}$ and $700-850 \mathrm{hPa}$ are eliminated in summer, and the root-mean-square error (RMSE) for the MP2003 simulation is also significantly improved. In winter, the bias in the MP2003 simulation is significantly reduced below $700 \mathrm{hPa}$, and the RMSE in the MP2003 simulation at $700 \mathrm{hPa}$ is significantly improved. Figure 17 shows the results of the specific humidity verification, where MP2003 was drier than MP1702 at $700-850 \mathrm{hPa}$, and the RMSE was significantly improved at $700 \mathrm{hPa}$, but significantly degraded at $850 \mathrm{hPa}$. The water vapor in the model was originally negatively biased, but the MP1702 simulation might have compensated for this by overevaporating rain. The cooling caused by excess evaporation also caused a low-temperature bias in the lower level. Eliminating negative biases, such as lower layer low-temperature bias and frequency of light rainfall, supports the correctness of the change to the MP2003 simulation.

Both Figs. 16 and 17 indicate that the experiments with MP2003 are overall superior to those with MP1702 regarding temperature and water vapor fields. The improvement of the cloud microphysics scheme has a positive effect on the overall skill of the NWP.

\section{Conclusions}

In this study, we verified the cloud microphysics scheme of the JMA regional model using GPM core-satellite observations. Results showed that there was a very large error in cloud fields in the original scheme. The low $T_{B}$ of GMI was not reproduced because of the lack of significant amount of cloud ice. The reflectivity of $\mathrm{Ku}$ and $\mathrm{Ka}$ radar was underestimated in both the lower and upper layers because of low rainfall and small particles in the lower layers and a smaller amount of snow in the upper layer for solid precipitation. From the comparison of the $Z_{m}(\mathrm{Ka})-Z_{m}(\mathrm{Ku})$ relationship, the amount of graupel was found to be large.

Based on the evaluations from the GPM satellite observation, we used the single-column kinematic model to identify the cause of the error of the original cloud microphysics scheme (MP1702). Through sensitivity experiments using the single-column kinematic model, we made the following three changes and constructed a new cloud microphysics scheme (MP2003). First, the conversion rate from cloud ice to snow was changed. Second, the terminal velocity of cloud ice was modified. Third, the size 
(a)
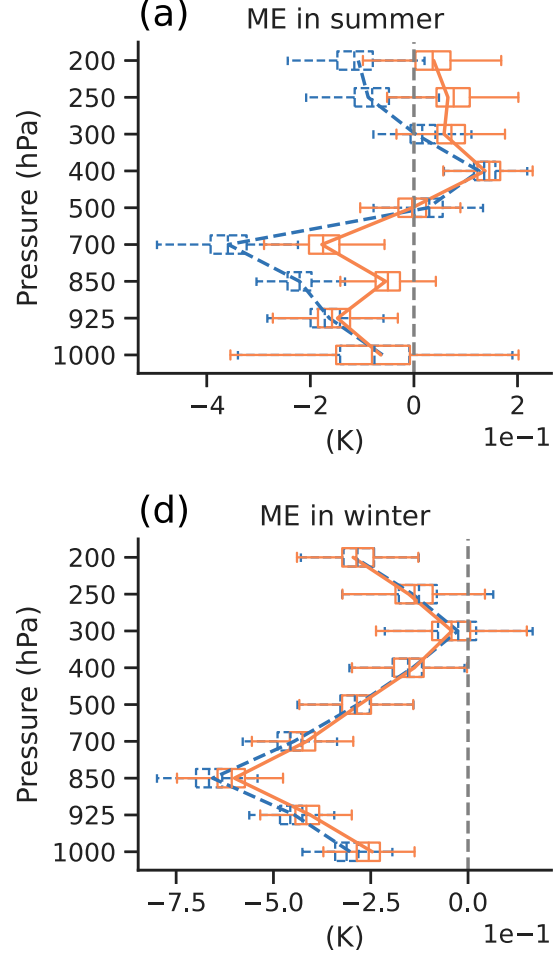

(b) Diff. ME in summer

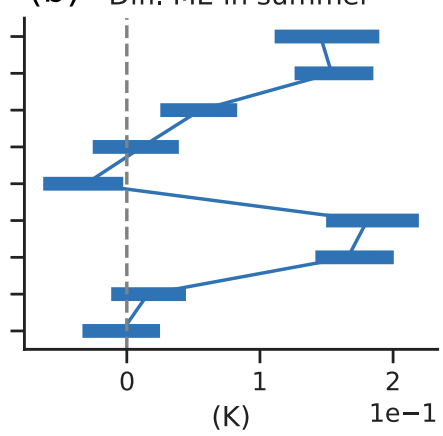

(e) Diff. ME in winter

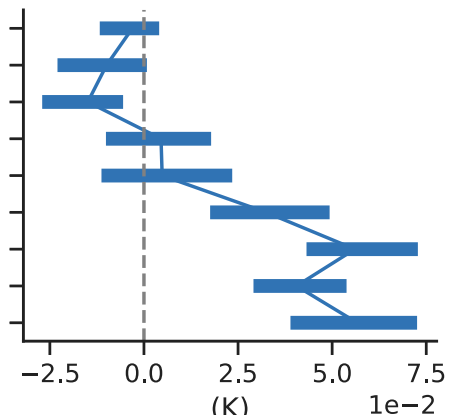

(c) Diff. RMSE in summer

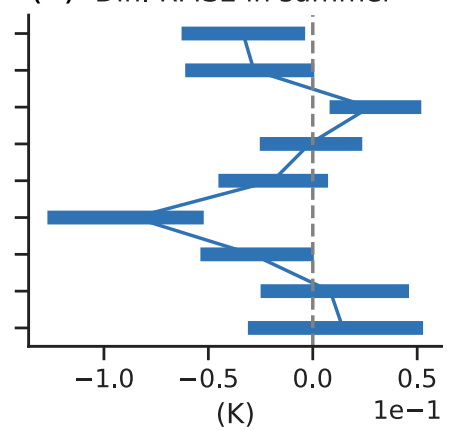

(f) Diff. RMSE in winter

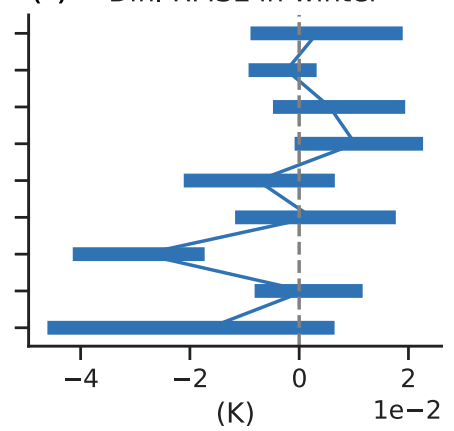

FIG. 16. Verification of temperature forecast in the upper air against sonde data. (a),(d) Mean error (ME) of the MP1702 simulation (blue) and MP2003 simulation (orange). (b),(e) ME of the MP2003 simulation minus the MP1702 simulation. (c),(f) Root-mean-square error (RMSE) of the MP2003 simulation minus the MP1702 simulation. (top) Scores in the summer experiment and (bottom) scores in the winter experiment. (a),(d) The box-and-whisker plots show the 0th, 25th, 50th, 75th, and 100th percentiles. (b),(c),(e),(f) The error bars show a $95 \%$ confidence interval calculated using the bootstrap method.

distribution of rain particles was modified from the $\mathrm{AB}$ scheme to the MP scheme.

The NWP forecast experiments were conducted by comparing the NWP model with MP1702 and MP2003. The precipitation forecast validation showed significant improvement for weak precipitation. In the sonde validation, the biases of specific humidity improved in the lower layers, and the RMSE of specific humidity is improved at $700 \mathrm{hPa}$ in the summer experiment and worsened at $850 \mathrm{hPa}$ in the summer experiment. Atmospheric temperature prediction also successfully eliminated the low-temperature bias in the upper and lower layers.

We investigated the improvement of a single-moment bulk cloud microphysics scheme (MP1702, MP2003). This type of cloud microphysics scheme is simple; however, other complicated and sophisticated schemes are used in research models, such as multimoment schemes or spectral bin schemes. Although this study is within the scope of comparable results for the two simple schemes, the results indicate that prediction accuracy is improved by enhancing the total balance of processes in microphysics scheme. Finally, we conclude that combining each process is more important for the overall performance of the cloud microphysics scheme and that introducing a partially advanced scheme does not improve the prediction. It is also speculated that schemes might also depend on the areas, such as the polar or tropical region or the midlatitude zone, indicating that a scheme developed at one region will not necessarily work well in other regions.

We also found that compensation errors affect the overall performance of the cloud microphysics scheme. The model has biases because of initial conditions, boundary conditions, and approximations in various physical processes. In the new scheme, MP2003, the water content distribution improved upon changing the bias at $850 \mathrm{hPa}$ to a negative bias, but the difference from the observation became larger. However, the prediction accuracy for other altitudes and temperatures improved. The original scheme, MP1702, could compensate for the water vapor bias in the model at the expense of the prediction accuracy of hydrometeors distribution in the atmosphere. If the model has a compensation error, it will be challenging to upgrade even if the model is improved correctly because the unfairly compensated score will be partially degraded.

In this study, the model was upgraded based on GPM observations and verified in detail for precipitation. This upgrade was introduced into the JMA's operational mesoscale NWP system on 26 March 2020 (Ikuta et al. 2020). We improved the cloud microphysics scheme, assuming that a model with better reproducibility of hydrometeor fields provides better forecasting ability. However, many more observations of clouds will be available in the future as new satellites are launched. Moreover, the accuracy of individual precipitation events needs to be improved. These issues will be clarified in the future using the 
(a) ME in summer

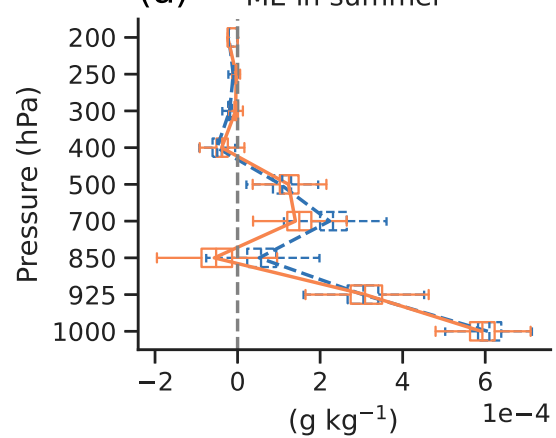

(d)

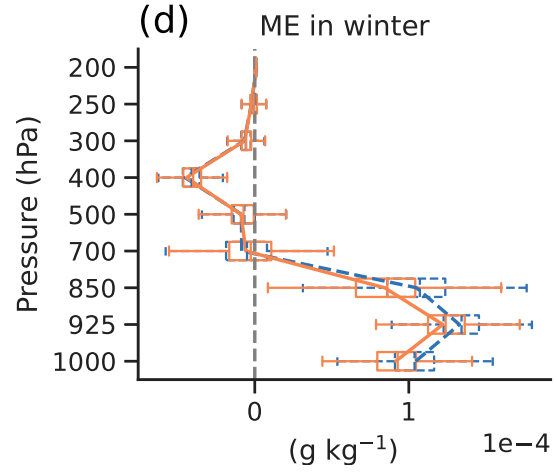

(b) Diff. ME in summer

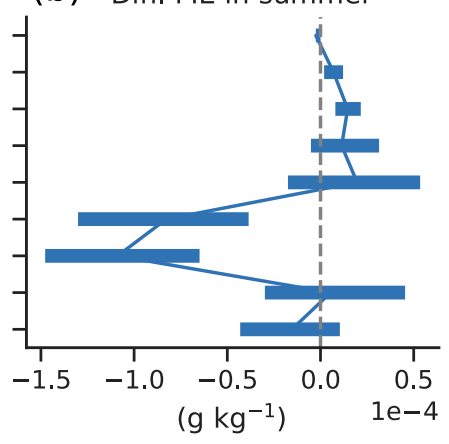

(e) Diff. ME in winter

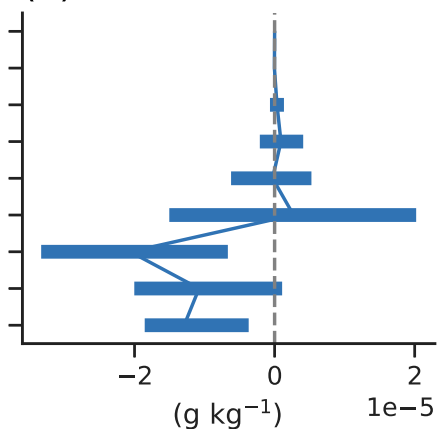

(c) Diff. RMSE in summer

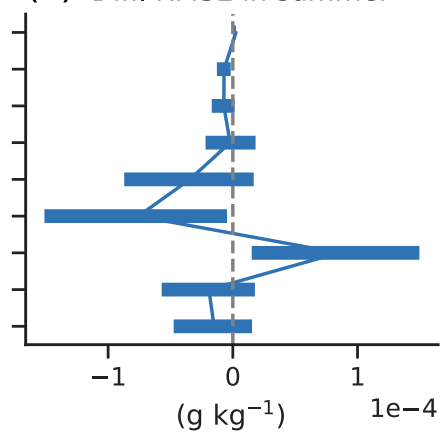

(f) Diff. RMSE in winter

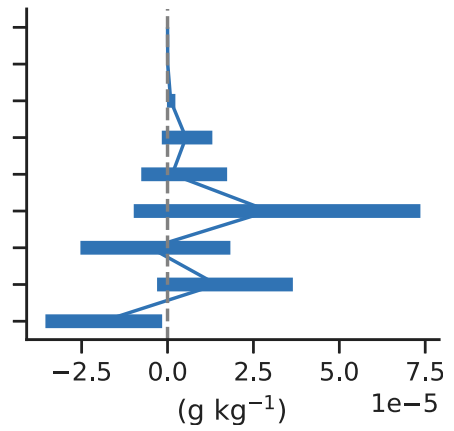

FIG. 17. As in Fig. 16, but for the specific humidity.

results of other satellite data, including the EarthCARE satellite mission (Illingworth et al. 2015) or ground-based radar network (e.g., ULTIMATE; Roh and Satoh 2021; Satoh 2021).

Acknowledgments. This study was supported by the second Research Announcement on the Earth Observations from the Japan Aerospace Exploration Agency. We wish to thank the colleagues at JMA for useful discussions. We also thank the three anonymous reviewers for comments that helped to greatly improve the manuscript.

\section{REFERENCES}

Abel, S. J., and B. J. Shipway, 2007: A comparison of cloudresolving model simulations of trade wind cumulus with aircraft observations taken during RICO. Quart. J. Roy. Meteor. Soc., 133, 781-794, https://doi.org/10.1002/qj.55.

— , and I. A. Boutle, 2012: An improved representation of the raindrop size distribution for single-moment microphysics schemes. Quart. J. Roy. Meteor. Soc., 138, 2151-2162, https:// doi.org/10.1002/qj.1949.

Barreyat, M., P. Chambon, J.-F. Mahfouf, G. Faure, and Y. Ikuta, 2021: A 1D Bayesian inversion applied to GPM microwave imager observations: Sensitivity studies. J. Meteor. Soc. Japan, 99, 1045-1070, https://doi.org/10.2151/jmsj.2021-050.

Bauer, P., E. Moreau, F. Chevallier, and U. O'Keeffe, 2006: Multiple-scattering microwave radiative transfer for data assimilation applications. Quart. J. Roy. Meteor. Soc., 132, 12591281, https://doi.org/10.1256/qj.05.153.

Bigg, E. K., 1953: The formation of atmospheric ice crystals by the freezing of droplets. Quart. J. Roy. Meteor. Soc., 79, 510-519, https://doi.org/10.1002/qj.49707934207.
Brown, P. R. A., and P. N. Francis, 1995: Improved measurements of the ice water content in cirrus using a total-water probe. J. Atmos. Oceanic Technol., 12, 410-414, https://doi.org/ 10.1175/1520-0426(1995)012<0410:IMOTIW>2.0.CO;2.

Chambon, P., S. Q. Zhang, A. Y. Hou, M. Zupanski, and S. Cheung, 2014: Assessing the impact of pre-GPM microwave precipitation observations in the Goddard WRF ensemble data assimilation system. Quart. J. Roy. Meteor. Soc., 140, 1219-1235, https://doi.org/10.1002/qj.2215.

Chern, J.-D., W.-K. Tao, S. E. Lang, X. Li, and T. Matsui, 2020: Evaluating precipitation features and rainfall characteristics in a multi-scale modeling framework. J. Adv. Model. Earth Syst., 12, e2019MS002007, https://doi.org/10.1029/ 2019MS002007.

Cotton, R. J., and Coauthors, 2013: The effective density of small ice particles obtained from in situ aircraft observations of midlatitude cirrus. Quart. J. Roy. Meteor. Soc., 139, 1923-1934, https://doi.org/10.1002/qj.2058.

Duruisseau, F., P. Chambon, G. Faure, and A. Geer, 2018: Development of an active sensor module for the RTTOVSCATT radiative transfer simulator. Ninth IPWG Workshop, Seoul, South Korea, IPWG, JP1.7, https://www.isac.cnr.it/ ipwg/meetings/seoul-2018/Posters/P1-21_Duruisseau.pdf.

Eito, H., and K. Aonashi, 2009: Verification of hydrometeor properties simulated by a cloud-resolving model using a passive microwave satellite and ground-based radar observations for a rainfall system associated with the baiu front. J. Meteor. Soc. Japan, 87A, 425-446, https://doi.org/10.2151/jmsj.87A.425.

Fabry, F., and W. Szyrmer, 1999: Modeling of the melting layer. Part II: Electromagnetic. J. Atmos. Sci., 56, 3593-3600, https://doi.org/ 10.1175/1520-0469(1999)056<3593:MOTMLP>2.0.CO;2.

Ferrier, B. S., W.-K. Tao, and J. Simpson, 1995: A doublemoment multiple-phase four-class bulk ice scheme. Part II: 
Simulations of convective storms in different large-scale environments and comparisons with other bulk parameterizations. J. Atmos. Sci., 52, 1001-1033, https://doi.org/10.1175/ 1520-0469(1995)052<1001:ADMMPF>2.0.CO;2.

Field, P. R., A. J. Heymsfield, and A. Bansemer, 2007: Snow size distribution parameterization for midlatitude and tropical ice clouds. J. Atmos. Sci., 64, 4346-4365, https://doi.org/10.1175/ 2007JAS2344.1.

Fielding, M. D., and M. Janisková, 2020: Direct 4D-Var assimilation of space-borne cloud radar reflectivity and lidar backscatter. Part I: Observation operator and implementation. Quart. J. Roy. Meteor. Soc., 146, 3877-3899, https://doi.org/10.1002/qj.3878.

Geer, A. J., and P. Bauer, 2011: Observation errors in all-sky data assimilation. Quart. J. Roy. Meteor. Soc., 137, 2024-2037, https://doi.org/10.1002/qj.830.

_ , and Coauthors, 2018: All-sky satellite data assimilation at operational weather forecasting centres. Quart. J. Roy. Meteor. Soc., 144, 1191-1217, https://doi.org/10.1002/qj.3202.

Hashino, T., M. Satoh, Y. Hagihara, T. Kubota, T. Matsui, T. Nasuno, and H. Okamoto, 2013: Evaluating cloud microphysics from NICAM against CloudSat and CALIPSO. J. Geophys. Res. Atmos., 118, 7273-7292, https://doi.org/ 10.1002/jgrd.50564.

— simulated by NICAM with A-train. J. Geophys. Res. Atmos., 121, 7041-7063, https://doi.org/10.1002/2016JD024775.

Hou, A. Y., and Coauthors, 2014: The Global Precipitation Measurement Mission. Bull. Amer. Meteor. Soc., 95, 701-722, https://doi.org/10.1175/BAMS-D-13-00164.1.

Iguchi, T., 2020: Dual-Frequency Precipitation Radar (DPR) on the Global Precipitation Measurement (GPM) Mission's Core Observatory. Satellite Precipitation Measurement, Springer International Publishing, V. Levizzani et al., Eds., 183-192, https://doi.org/10.1007/978-3-030-24568-9_11.

_ , and Coauthors, 2018: GPM/DPR Level-2 Algorithm Theoretical Basis Document (V06). 127 pp., https://www.eorc.jaxa.jp/GPM/ doc/algorithm/ATBD_DPR_201811_with_Appendix3b.pdf.

Ikuta, Y., and Coauthors, 2020: A new data assimilation system and upgrading of physical processes in JMA's meso-scale NWP system. WGNE Res. Act. Earth System Model., 50, 1.07-1.08, http://bluebook.meteoinfo.ru/uploads/2020/docs/ 01_Ikuta_Yasutaka_MAMSM2003.pdf.

_- K. Okamoto, and T. Kubota, 2021: One-dimensional maximum-likelihood estimation for spaceborne precipitation radar data assimilation. Quart. J. Roy. Meteor. Soc., 147, 858-875, https://doi.org/10.1002/qj.3950.

Illingworth, A. J., and Coauthors, 2015: The EarthCARE satellite: The next step forward in global measurements of clouds, aerosols, precipitation, and radiation. Bull. Amer. Meteor. Soc., 96, 1311-1332, https://doi.org/10.1175/BAMS-D-12-00227.1.

Japan Meteorological Agency, 2019: Outline of the operational numerical weather prediction at the Japan Meteorological Agency. Appendix to WMO Technical Progress Report on the Global Data-Processing and Forecasting System and Numerical Weather Prediction, 229 pp., https://www.jma.go.jp/jma/jmaeng/jma-center/nwp/outline2019-nwp/index.htm.

__ 2020: Suuchi Yohou Kenshu Text 2020 (in Japanese). Japan Meteorological Agency Forecast Department, 153 pp., https:// www.jma.go.jp/jma/kishou/books/nwptext/nwptext.html.

Kojima, M., and Coauthors, 2012: Dual-frequency precipitation radar (DPR) development on the global precipitation measurement (GPM) core observatory. Proc. SPIE, 8528, 85281A, https://doi.org/10.1117/12.976823.
Kotsuki, S., K. Terasaki, and T. Miyoshi, 2014: GPM/DPR precipitation compared with a $3.5-\mathrm{km}$-resolution NICAM simulation. SOLA, 10, 204-209, https://doi.org/10.2151/sola.2014-043.

Kozu, T., and Coauthors, 2001: Development of precipitation radar onboard the Tropical Rainfall Measuring Mission (TRMM) satellite. IEEE Trans. Geosci. Remote Sens., 39, 102-116, https://doi.org/10.1109/36.898669.

Kuba, N., T. Seiki, K. Suzuki, W. Roh, and M. Satoh, 2020: Evaluation of rain microphysics using a radar simulator and numerical models: Comparison of two-moment bulk and spectral bin cloud microphysics schemes. J. Adv. Model. Earth Syst., 12, e2019MS001891, https://doi.org/10.1029/2019MS001891.

Kubota, T., T. Iguchi, M. Kojima, L. Liao, T. Masaki, H. Hanado, R. Meneghini, and R. Oki, 2016: A statistical method for reducing sidelobe clutter for the $\mathrm{Ku}$-band precipitation radar on board the GPM core observatory. J. Atmos. Oceanic Technol., 33, 1413-1428, https://doi.org/10.1175/JTECH-D-15-0202.1.

Kummerow, C., W. Barnes, T. Kozu, J. Shiue, and J. Simpson, 1998: The Tropical Rainfall Measuring Mission (TRMM) sensor package. J. Atmos. Oceanic Technol., 15, 809-817, https://doi.org/ 10.1175/1520-0426(1998)015<0809:TTRMMT>2.0.CO;2.

Le, M., and V. Chandrasekar, 2013: Hydrometeor profile characterization method for dual-frequency precipitation radar onboard the GPM. IEEE Trans. Geosci. Remote Sens., 51, 3648-3658, https://doi.org/10.1109/TGRS.2012.2224352.

Li, X., W.-K. Tao, T. Matsui, C. Liu, and H. Masunaga, 2010: Improving a spectral bin microphysical scheme using TRMM satellite observations. Quart. J. Roy. Meteor. Soc., 136, 382399, https://doi.org/10.1002/qj.569.

Lin, Y.-L., R. D. Farley, and H. D. Orville, 1983: Bulk parameterization of the snow field in a cloud model. J. Climate Appl. Meteor., 22, 1065-1092, https://doi.org/10.1175/1520-0450(1983) 022<1065:BPOTSF $>2.0 . \mathrm{CO} ; 2$.

Liu, G., 2008: A database of microwave single-scattering properties for nonspherical ice particles. Bull. Amer. Meteor. Soc., 89, 1563-1570, https://doi.org/10.1175/2008BAMS2486.1.

Masunaga, H., M. Satoh, and H. Miura, 2008: A joint satellite and global cloud-resolving model analysis of a Madden-Julian oscillation event: Model diagnosis. J. Geophys. Res., 113, D17210, https://doi.org/10.1029/2008JD009986.

Matsui, T., X. Zeng, W.-K. Tao, H. Masunaga, W. S. Olson, and S. Lang, 2009: Evaluation of long-term cloud-resolving model simulations using satellite radiance observations and multifrequency satellite simulators. J. Atmos. Oceanic Technol., 26, 1261-1274, https://doi.org/10.1175/ 2008JTECHA1168.1.

_ J.-D. Chern, W.-K. Tao, S. Lang, M. Satoh, T. Hashino, and T. Kubota, 2016: On the land-ocean contrast of tropical convection and microphysics statistics derived from TRMM satellite signals and global storm-resolving models. J. Hydrometeor., 17, 1425-1445, https://doi.org/10.1175/JHM-D-15-0111.1.

Mitchell, D. L., 1996: Use of mass- and area-dimensional power laws for determining precipitation particle terminal velocities. J. Atmos. Sci., 53, 1710-1723, https://doi.org/10.1175/15200469(1996)053<1710:UOMAAD>2.0.CO;2.

Murakami, M., 1990: Numerical modeling of dynamical and microphysical evolution of an isolated convective cloud. J. Meteor. Soc. Japan, 68, 107-128, https://doi.org/10.2151/ jmsj1965.68.2_107.

Nagata, K., 2011: Quantitative precipitation estimation and quantitative precipitation forecasting by the Japan Meteorological Agency. Tech. Rev. 13, RSMC, Tokyo, 14 pp., http://www.jma.go.jp/jma/ jma-eng/jma-center/rsmc-hp-pub-eg/techrev/text13-2.pdf. 
Okamoto, K., K. Aonashi, T. Kubota, and T. Tashima, 2016: Experimental assimilation of the GPM core observatory DPR reflectivity profiles for Typhoon Halong (2014). Mon. Wea. Rev., 144, 2307-2326, https://doi.org/10.1175/MWR-D-15-0399.1.

Roh, W., and M. Satoh, 2014: Evaluation of precipitating hydrometeor parameterizations in a single-moment bulk microphysics scheme for deep convective systems over the tropical central Pacific. J. Atmos. Sci., 71, 2654-2673, https://doi.org/ 10.1175/JAS-D-13-0252.1.

— , and - 2021: An introduction to the ULTIMATE project in Japan. 23rd EGU General Assembly, EGU, EGU21-11901, https://doi.org/10.5194/egusphere-egu21-11901.

,-- , and T. Nasuno, 2017: Improvement of a cloud microphysics scheme for a global nonhydrostatic model using TRMM and a satellite simulator. J. Atmos. Sci., 74, 167-184, https://doi.org/10.1175/JAS-D-16-0027.1.

- _- T. Hashino, H. Okamoto, and T. Seiki, 2020: Evaluations of the thermodynamic phases of clouds in a cloud-system-resolving model using CALIPSO and a satellite simulator over the Southern Ocean. J. Atmos. Sci., 77, 3781-3801, https://doi.org/10.1175/JAS-D-19-0273.1.

Satoh, M., 2021: ULTIMATE: Ultra-site for measuring atmosphere of Tokyo metropolitan environment (in Japanese). J. Remote Sens. Soc. Japan, 41, 133-139, https://doi.org/10.11440/rssj.41.133.

Saunders, R., and Coauthors, 2018: An update on the RTTOV fast radiative transfer model (currently at version 12). Geosci. Model Dev., 11, 2717-2737, https://doi.org/10.5194/gmd-11-2717-2018.

Seto, S., T. Iguchi, R. Meneghini, J. Awaka, T. Kubota, T. Masaki, and N. Takahashi, 2021: The precipitation rate retrieval algorithms for the GPM dual-frequency precipitation radar. J. Meteor. Soc. Japan, 99, 205-237, https://doi.org/10.2151/jmsj.2021-011.

Shimpo, A., and Coauthors, 2019: Primary factors behind the heavy rain event of July 2018 and the subsequent heat wave in Japan. SOLA, 15A, 13-18, https://doi.org/10.2151/sola.15A-003.

Shipway, B. J., and A. A. Hill, 2012: Diagnosis of systematic differences between multiple parametrizations of warm rain microphysics using a kinematic framework. Quart. J. Roy. Meteor. Soc., 138, 2196-2211, https://doi.org/10.1002/qj.1913.

Skofronick-Jackson, G., and Coauthors, 2017: The Global Precipitation Measurement (GPM) mission for science and society. Bull. Amer. Meteor. Soc., 98, 1679-1695, https://doi.org/10.1175/BAMS-D-1500306.1 .

Smith, R. N. B., 1990: A scheme for predicting layer clouds and their water content in a general circulation model. Quart. J. Roy. Meteor. Soc., 116, 435-460, https://doi.org/10.1002/qj.49711649210.

Swales, D. J., R. Pincus, and A. Bodas-Salcedo, 2018: The cloud feedback model intercomparison project observational simulator package: Version 2. Geosci. Model Dev., 11, 77-81, https://doi.org/10.5194/gmd-11-77-2018.

Wilson, D. R., and S. P. Ballard, 1999: A microphysically based precipitation scheme for the UK Meteorological Office Unified Model. Quart. J. Roy. Meteor. Soc., 125, 1607-1636, https://doi.org/10.1002/qj.49712555707.

Yuter, S. E., and R. A. Houze, 1995: Three-dimensional kinematic and microphysical evolution of Florida cumulonimbus. Part II: Frequency distributions of vertical velocity, reflectivity, and differential reflectivity. Mon. Wea. Rev., 123, 1941-1963, https:// doi.org/10.1175/1520-0493(1995)123<1941:TDKAME >2.0.CO;2. 